\title{
Bi-Sourcing in the Global Economy
}

\author{
Julan Du, Yi Lu and Zhigang Tao*
}

December $20^{\text {th }}, 2005$

\begin{abstract}
In organizing production, many firms conduct bi-sourcing, i.e., acquiring the same set of inputs by both buying from external suppliers (outsourcing) and producing in componentmanufacturing subsidiries (insourcing). We show that, by adopting the bi-sourcing strategy, firms can use the in-house production to mitigate the holdup problem in outsourcing and introduce elements of competition from outsourcing in dealing with the incentive problem in insourcing (the cross-threat effect). When firms conduct bi-sourcing in the global economy consisting of high-waged North and low-waged South, they need to make the location choice for both insourcing and outsourcing. We find that the low wage in the South can stimulate investment incentive by component suppliers no matter whether they are internal or external suppliers (the cost difference effect). Furthermore, firms may achieve better cross-threat effect by locating overly strong (or weak) supplier in the disadvantageous North (or advantageous South) (the balancing effect). We demonstrate that locating both internal and external suppliers in the South often yields the highest production efficiency among all possible patterns of bi-sourcing. Our results on bi-sourcing patterns are consistent with some recent trends in world trade such as the growing vertical specialization, intrafirm trade and complementarity between foreign direct investments and trade.
\end{abstract}

Keywords: Multinational firms, global sourcing, property-rights theory, vertical integration, outsourcing, bi-sourcing

JEL Classification Numbers: D23, F21, F23, L22, L23

\footnotetext{
* Corresponding author: Zhigang Tao, School of Business, The University of Hong Kong, Pokfulam Road, Hong Kong. Tel: 852-2857-8223; Fax: 852-2858-5614; Email: ztao@business.hku.hk. Julan Du and Yi Lu are from Department of Economics, Chinese University of Hong Kong and School of Business, The University of Hong Kong respectively. We would like to thank Ivan Png, Larry Qiu, Michael Riordan, Thomas Ross and participants in the 2005 Econometric Society World Congress, the 2005 Summer Workshop on Industrial Organization and Management Strategy at Tsinghua University, and the International Conference on Trade and Investment in East Asia at Fudan University for their helpful comments.
} 


\section{Introduction}

In organizing production, a firm needs to decide whether to produce intermediate inputs internally (insourcing) or purchase them from external suppliers (outsourcing). While much emphasis has been placed on the growth of outsourcing in business magazines and newspapers, an emerging interesting arrangement is worth investigating. Many firms are acquiring the same set of inputs by both purchasing from external suppliers and carrying out in-house production in component-manufacturing subsidiaries. We call it bi-sourcing as it contains both outsourcing and insourcing. Bi-sourcing has become a widely-adopted business strategy.

Nokia provides one example. To ensure the supply of electronic components for the production of mobile phones and networks, Nokia operates ten manufacturing plants in nine countries to produce semiconductors, microprocessors, memory devices, micro controllers and displays. However, Nokia does not rely solely on insourcing. It purchases a large proportion of the components from a global network of suppliers. For instance, in 2003, outsourcing covered an estimated $20-25 \%$ of Nokia's mobile phone engines in volume (Nokia, 2003).

The bi-sourcing of long-term maintenance by U.S. airlines provides another example. It is reported that half of U.S. carriers' heavy-overhaul work is conducted by in-house mechanics, while the other half is now performed by outside vendors in the U.S. and overseas, which is a big surge from less than a third in 1990 (Carey and Frangos, 2005).

In recent years, with IT services gaining importance, business corporations have increasingly adopted a set of internal and external providers in the global economy (Cohen and Young, 2006). For example, DuPont has created what it calls a global IT alliance that blends services from more than ten service providers and DuPont's own internal resources to meet the demands of the business. Similarly, the accounts-payable process of GMS, a global manufacturing and service firm, has in fifteen years moved from being highly centralized and internal, to globally decentralized and internal, to globally decentralized with a mix of internal and external resources.

Why do companies conduct bi-sourcing in the global economy? To answer this question, we first look at the strength and weakness of insourcing and outsourcing in a closed-economy model, from which we can understand how bi-sourcing, as a combination of insourcing and outsourcing, may perform better than both insourcing and outsourcing.

In outsourcing, the final good producer and the component manufacturer retain ownership and control over assets for downstream and upstream production separately. According to the property-rights theory of the firm, the 
ownership and control of assets by the component manufacturer can stimulate its incentive to make investments and improve productivity; however, it also allows the component manufacturer to pose greater holdup threat to the downstream firm. The component manufacturer may threaten not to deliver the agreed amount of inputs with the agreed specifications at the agreed date, which may bring to the downstream firm the risk of a halt to its production but may allow the component manufacturer to capture a larger share of total surplus. Corporations are clearly aware of this potential return and risk in conducting outsourcing. For instance, Nokia finds that outsourcing enables the company to obtain inputs produced with the state-of-the-art technology and adds flexibility to its manufacturing activities. However, Nokia also understands that outsourcing involves the risk that the timely delivery of components and the quality, safety and other standards for the inputs may not be guaranteed (Nokia, 2003).

Insourcing (with vertical integration of component manufacturing by the final good producer or the firm) puts the assets for the two successive stages of production under a common ownership. By owning and controlling the assets for component manufacturing, the firm can effectively minimize the potential risk of the holdup problem. Nonetheless, the component manufacturer, who does not own any assets essential to producing the intermediate goods, has lower incentives to make investments to enhance production efficiency than she does in the case of outsourcing.

By conducting insourcing and outsourcing simultaneously, bi-sourcing may not only help the firm add up the strengths of both strategies, but also mitigate the weakness of either insourcing or outsourcing by employing cross threat in its negotiations with the internal and external suppliers. In bargaining with the external supplier, the firm, with the internal supply from the component-manufacturing subsidiary, can minimize the potential efficiency losses from the holdup problem. In negotiating with the internal supplier, the provision of inputs from the external supplier helps introduce elements of competition into the integrated firm. If the internal supplier, as a result of lack of incentives, cannot produce quality components with updated technology, the firm can rely more on the external component manufacturer. This forces the internal supplier to make relationship-specific investments to improve productivity.

The example of Samsung provides a vivid illustration of how bi-sourcing may improve efficiency as compared with insourcing. In October 2002, Samsung started a fifth-generation LCD production line in Chonan, South Korea, which served as an internal supplier of the component. In May 2003, Sumitomo Chemical invested 28 billion Japanese Yen to establish the second color filter plant in Pyungtaek, South Korea and built up an additional 
fifth-generation LCD production line. Samsung acquires the LCD from both its internal manufacturer in Chonan and the external supplier in Pyungtaek. The existence of the external supplier effectively introduces competitive pressures onto the internal supplier and forces the internal supplier to make relation-specific investments and improve productivity. Hiromasa Yonekura, the president of Sumitomo Chemicals, commented on Samsung's strategy that "they really press these departments to compete". ${ }^{1}$

The choice of organizational forms also depends on the organizational fixed costs. Both insourcing and outsourcing involve significant fixed costs. As bi-sourcing contains both insourcing and outsourcing, it is expected to incur the fixed costs of both insourcing and outsourcing, and thus have the highest fixed costs among the three organizational forms. Our theory thus predicts that only those firms with the highest productivity will adopt bisourcing because their revenues are large enough to cover the extra organizational fixed costs.

Our model is then extended to the global-economy setup that consists of the high-waged North and the low-waged South. In addition to deciding on the organizational form, the firm also chooses the location of component suppliers. A firm with its headquarters in the North can locate both the internal and external component suppliers in the North or in the South. Alternatively, the firm can choose to locate internal and external suppliers separately with one in the North and the other in the South.

What drives the location choice of the internal and external component suppliers? We identify two factors. One is the cost difference effect. With the lower wage in the South as compared with the North, the suppliers (both external and internal) enjoy cost advantage and make more investments, which enhances production efficiency. The other factor is the balancing effect. The strength of bi-sourcing lies in that the firm utilizes cross threat to minimize the potential efficiency losses from the external supplier's holdup problem and from the internal supplier's lack of incentive in making relationshipspecific investments. Specifically, the firm uses the investment of one supplier to enhance its bargaining power in negotiating with the other supplier. To maximize the effectiveness of cross threat, the firm does not want either component maker to be too strong relative to the other one. For example, when the internal supplier makes too much investment, it may suppress the incentive of the external supplier to invest because the firm's default option in the bargaining is so powerful that it overwhelms the external supplier. In

\footnotetext{
${ }^{1}$ We are grateful to Ivan Png for providing this example. This case is based on "Samsung Electronics Announces the Industry's Largest 46 Inch TFT LCD for High Definition of TVs" (Company Press Release, October 25th 2002) and "Sumitomo Chemical to Double LCD Color Filter Capacity in Korea" (Company Press Release, May 12th 2003).
} 
the global economy, the firm can use the location choice of component suppliers, say, locating overly strong (or weak) supplier in the disadvantageous North (or the advantageous South), to help balance the relative bargaining power of the internal and external suppliers so as to achieve an ideal cross threat effect in negotiations.

The optimal bi-sourcing strategy is determined with the interplay of the cost difference effect and the balancing effect. In many cases we have considered, locating both internal and external suppliers in the South yields the highest production efficiency among all possible patterns of bi-sourcing strategy. This is consistent with some of the recent trends in world trade development such as the growing significance of vertical specialization and intrafirm trade and the complementarity between foreign direct investments and trade.

Our paper is related to a growing literature on the choice between insourcing and outsourcing in the global economy. These studies make use of recent advances in the economic theory of organizations such as transaction costs economics (TCE), property-rights theory (PRT), principal-agent theory $(\mathrm{PA})$ and authority-delegation theory $(\mathrm{ADT})^{2}$ to explain the growing vertical disintegration of international production. ${ }^{3}$ Our paper is most closely related to Antràs and Helpman (2004). They integrate the property-rights theory of firm and the heterogeneity of firm productivity (Melitz (2003)) into a general equilibrium model of international trade to study the choice between insourcing and outsourcing in the global economy. However, in their paper as well as related papers in this strand of literature, outsourcing and insourcing are two distinct and separate modes of acquiring intermediate inputs. In contrast, we focus on the emerging pattern of bi-sourcing and its structure in the global economy, where insourcing and outsourcing are simultaneously adopted by final good producers in various countries.

Our paper is also associated with the industrial organization literature on second sourcing or dual sourcing, which includes Anton and Yao (1987), Shepard (1987), Farrell and Gallini (1988), Riordan and Sappington (1989), Dick (1990) and Kerschbamer and Tournas (2003). These papers study why a buyer uses either two or more outside or inside sellers to supply the goods. Their key insight lies in that introducing competition on the sellers' side

\footnotetext{
${ }^{2}$ See Williamson $(1975,1985)$ for the TCE, Grossman and Hart (1986), Hart and Moore (1990) and Hart (1995) for the PRT, Holmstrom and Milgrom (1991, 1994) for the PA, and Aghion and Tirole (1997) for the ADT.

${ }^{3}$ The papers include McLaren (1999), Grossman and Helpman (2002, 2004, 2005), Puga and Trefler (2002), Antràs (2003), Marin and Verdier (2003), Antràs and Helpman (2004), Antràs, Garicano and Rossi-Hansberg (2005), Grossman, Helpman and Szeidl (2005), etc. See Antràs (2005) and Spencer (2005) for literature review.
} 
can constrain their opportunistic behavior and thus reduce the adverse effect of informational disadvantage on the buyer's side. Clearly, we differ from the dual sourcing literature in that we are dealing with multiple suppliers that include both internal and external ones rather than multiple internal suppliers or multiple external suppliers.

The rest of the paper is organized as follows. Section 2 lays out the basic model setup. The benchmark case of a closed economy model is analyzed in Section 3. In Section 4, we extend the benchmark model to the global economy. Section 5 concludes the paper.

\section{Basic Model Setup}

We extend the framework of Antràs and Helpman (2004) to study bi-sourcing. Consider an economy consisting of two sectors: a homogeneous good $(X)$ produced with the constant returns to scale technology and a continuum of differentiated goods $(Y)$ produced with the increasing returns to scale technology. There is a unit measure of consumers with the preference of the representative consumer given by

$$
U=X^{1-\mu} Y^{\mu}, Y=\left[\int_{\omega \in \Omega} y(\omega)^{\alpha} d \omega\right]^{1 / \alpha}, \quad 0<\alpha<1
$$

where $\mu$ represents the weight that the consumers put on the differentiated goods, $X$ is the consumption of the homogeneous good, $y(\omega)$ is the consumption of variety $\omega$ of the differentiated goods $Y, Y$ is the index of aggregate consumption of differentiated goods and the set $\Omega$ represents the mass of those goods. The elasticity of substitution between any two differentiated goods is $\sigma \equiv 1 /(1-\alpha)>1$. A higher value of $\sigma(\alpha)$ implies fiercer competition in the differentiated goods sector.

It is well known that the consumer preference of (1) leads to the inverse demand function for each variety $\omega$ of the differentiated goods:

$$
p(\omega)=\frac{\mu I}{Y}\left(\frac{y(\omega)}{Y}\right)^{\alpha-1}
$$

where $p(\omega)$ is the price of variety $\omega$ and $I$ denotes the consumers' total expenditure. For a given supplier of variety $\omega, Y$ and $I$ are treated as constants.

To produce any variety of the differentiated goods, two variety-specific inputs, $h(\omega)$ and $m(\omega)$, are jointly required, which are referred to as headquarters service and manufactured component respectively. The production of both inputs uses only one factor - labor. Each unit of $h(\omega)$ and $m(\omega)$ 
requires one unit of labor. In the closed-economy setting (Section 3), the wage rate is assumed to be a constant $w$; but this assumption will be relaxed in the global-economy setting (Section 4). The production function of differentiated good $y(\omega)$ is assumed to take the form of a Cobb-Douglas function

$$
y(\omega)=\theta\left[\frac{h(\omega)}{\eta}\right]^{\eta}\left[\frac{m(\omega)}{1-\eta}\right]^{1-\eta}, 0<\eta<1 .
$$

where $\theta$ is a firm-specific productivity parameter, and $\eta$ is a sector-specific parameter regarding the intensity of headquarters service in the production of differentiated good $\omega$ with a larger $\eta$ indicating a higher intensity of headquarters service. Combined with (2), it yields the revenue

$$
R=\mu I Y^{-\alpha} \theta^{\alpha}\left[\frac{h}{\eta}\right]^{\alpha \eta}\left[\frac{m}{1-\eta}\right]^{\alpha(1-\eta)}
$$

where the variety parameter $\omega$ is left out hereon as all the cases are symmetric.

There are two kinds of producers: final good producers, who provide variety-specific headquarters service $(h)$, and component makers, who supply variety-specific manufactured component $(m)$. We denote the final good producers by $H$ and the component makers by $M$. Every final good producer organizes the production process, combining the headquarters service and the manufactured component to make the differentiated good in terms of the production function (3). The final good producer supplies the headquarters service by itself; and henceforth, the final good producer and the headquarters are used interchangeably. In addition, it needs to arrange for the supply of the manufactured component. In the closed-economy setting (Section 3), the final good producer can set up a subsidiary making the component in-house (called insourcing and denoted by $I$ ), or contract with an external supplier for the manufactured component (called outsourcing and denoted by $O$ ), or both (called bi-sourcing and denoted by $B$ ). In the globaleconomy setting (Section 4), there is an additional location-choice decision between the high-waged North and the low-waged South for the component manufacturing.

The time line of the model is as follows. At time 0 , the final good producer makes the organizational and location choices. Ex ante investments in input production, including manufactured component $(m)$ and headquarters service $(h)$, are made at date 1 . At date $2, m$ is supplied and combined with $h$ to make the final product.

As in Antràs and Helpman (2004), we consider a setting of incomplete contracts. It is assumed that the precise nature of the required inputs is 
difficult to specify ex ante, and that, once revealed ex post, the nature of the required inputs is still not verifiable by a third party. As a result, the final good producer $H$ and component supplier $M$ cannot write enforceable contracts that specify the purchase of intermediate inputs with certain qualitative and quantitative qualifications for a certain price. As in Antràs and Helpman (2004), it is further assumed that the ex ante investments for input production are not contractible and neither is the sales revenue. There is a large literature regarding the informational assumptions needed for the contractual incompleteness to exist. But in this paper we take the contractual incompleteness as given and explore its impacts on the choice of the sourcing strategies in the global economy.

Without an enforceable contract written ex ante, the final good producer $H$ and component supplier $M$ bargain over the surplus value from trade at date 2 after they make their own investments at date 1 . Following the property-rights theory of the firm (Grossman and Hart (1986), Hart and Moore (1990), and Hart (1995)), it is assumed that the bargaining takes place in both outsourcing and insourcing and thus in all the three organizational forms we examine. Nevertheless, as ownership arrangements over the assets for component manufacturing confer the residual rights of control, the relative bargaining powers between $H$ and $M$ vary from outsourcing to insourcing and bi-sourcing, which will be elaborated further in Section 3.

\section{Bi-Sourcing in the Closed Economy}

In this section, we analyze the equilibrium in a closed-economy setting where the production of both components and final goods is carried out in one country. The decision to be made concerns only with the organizational choice. The final good producers or the headquarters can choose to have insourcing, or outsourcing, or bi-sourcing for the supply of components.

The three organizational forms differ from each other in terms of the fixed organizational costs. In the case of outsourcing, the final good producer $H$ and component supplier $M$ have arm's-length trading relationship, bearing market transactions costs such as the costs of $H$ searching for a suitable component manufacturer $M$, bargaining with $M$, and writing contracts with $M$. In the case of insourcing, $H$ and $M$ are vertically integrated into one firm. Though the market transactions costs per se may be reduced, $H$ needs to supervise $M$ in the production process, incurring substantial monitoring costs. Following Antràs and Helpman (2004), we assume that the fixed organizational costs of insourcing (denoted by $f_{I}$ ) are higher than those of outsourcing (denoted by $f_{O}$ ). In the scenario of bi-sourcing, insourcing and 
outsourcing coexist, and the final good producer $H$ needs to incur the fixed costs associated with both insourcing and outsourcing. We thus expect that bi-sourcing has the highest fixed organizational costs (denoted by $f_{B}$ ) among the three organizational forms. As a result, the fixed costs involved in the three organizational forms observe the following order ${ }^{4}$

$$
f_{B}>f_{I}>f_{O}
$$

The main difference among the three organizational forms, however, lies in their impacts on the investment incentive for input production and consequently the size of the trading surplus, which we turn to in the following subsections.

\subsection{Single Sourcing}

In single sourcing, the final good producer $H$ either signs a contract with $M$ to purchase the variety-specific component (i.e., single outsourcing) or integrates with $M$ to produce the component in-house (i.e., single insourcing). Afterwards, $H$ and $M$ make investments to produce headquarters service $h$ and manufactured component $m$ respectively. Then they bargain over the distribution of the surplus from the trading relationship.

Notice that we follow the property-rights theory of the firm by assuming that ex post bargaining still takes place even if $H$ vertically integrates $M$; nevertheless, as compared with outsourcing, the final good producer $H$ has greater bargaining power vis-a-vis the component supplier $M$. This is because, in the case of insourcing, with ownership and control over the assets for component manufacturing, $H$ can always fire the component supplier after the input investment is made and still enjoy part of the input investment so long as the original component supplier does not have some production capability that is irreplaceable. For simplicity of analysis, we follow Antràs and Helpman (2004) by assuming that the ex post bargaining process follows a generalized Nash bargaining game where $H$ has higher bargaining power in single insoursing (denoted by $\beta_{I} \in(0,1)$ ) than in single outsourcing (denoted by $\beta \in(0,1)$ ), i.e., $\beta_{I}>\beta$. Given that the headquarters service and manufactured component are variety-specific, it is further assumed that neither $H$ nor $M$ could get any value in case of bargaining failure.

Assume that the ex post bargaining is efficient. Then $H$ and $M$ will reach an agreement on the division of surplus $R$ at date $2 . H$ gets $\beta_{k} R$ and $M$ gets

\footnotetext{
${ }^{4}$ For convenience, the fixed costs $\left(f_{I}, f_{O}\right.$ and $\left.f_{B}\right)$ are expressed in terms of units of labor. We can obtain the monetary value of fixed costs by multiplying them by wage rate $w$.
} 
$\left(1-\beta_{k}\right) R$, where $\beta_{k}=\beta$ when $k=O$ and $\beta_{k}=\beta_{I}$ when $k=I$. At date 1 , the two parties choose to make investments in input production noncooperatively to maximize their respective payoffs. More specifically, $M$ and $H$ choose $m$ and $h$ to maximize $\left(1-\beta_{k}\right) R-w m$ and $\beta_{k} R-w h$ respectively. The total payoff of the two parties under single sourcing can be shown as follows:

$$
\pi_{k}=\phi_{k}(\mu I)^{\frac{1}{1-\alpha}} Y^{-\frac{\alpha}{1-\alpha}} \theta^{\frac{\alpha}{1-\alpha}}-w f_{k}
$$

where

$$
\begin{aligned}
\phi_{k} & =\alpha^{\frac{\alpha}{1-\alpha}} w^{-\frac{\alpha}{1-\alpha}}\left(\beta_{k}\right)^{\frac{\alpha}{1-\alpha} \eta}\left(1-\beta_{k}\right)^{\frac{\alpha}{1-\alpha}(1-\eta)}\left[1-\alpha\left(\beta_{k} \eta+\left(1-\beta_{k}\right)(1-\eta)\right)\right], \\
k & \in\{O, I\} .
\end{aligned}
$$

To save space, derivation of key equations and proof of all Lemmas and Propositions are contained in the Appendix.

\subsection{Bi-sourcing}

The scenario of bi-sourcing is more complicated as the final good producer $H$ obtains the manufactured component from two suppliers - one internal (denoted by $M_{1}$ ) and one external (denoted by $M_{2}$ ). The investments made by the internal and external suppliers are denoted by $m_{1}$ and $m_{2}$, respectively.

We define some notations here first

$$
\begin{aligned}
& R=\mu I Y^{-\alpha} \theta^{\alpha}\left[\frac{h}{\eta}\right]^{\alpha \eta}\left[\frac{m_{1}+m_{2}}{1-\eta}\right]^{\alpha(1-\eta)}, \\
& R_{1}=\mu I Y^{-\alpha} \theta^{\alpha}\left[\frac{h}{\eta}\right]^{\alpha \eta}\left[\frac{m_{1}}{1-\eta}\right]^{\alpha(1-\eta)}, \\
& R_{2}=\mu I Y^{-\alpha} \theta^{\alpha}\left[\frac{h}{\eta}\right]^{\alpha \eta}\left[\frac{m_{2}}{1-\eta}\right]^{\alpha(1-\eta)} .
\end{aligned}
$$

Expressions (7) denote the respective total revenues when both $M_{1}$ and $M_{2}$ supply the component, only $M_{1}$ supplies the component and only $M_{2}$ provides the component. In negotiations, the total revenue available to the three parties amounts to $R$, from which $H$ needs to pay $P_{1}$ to $M_{1}$ and $P_{2}$ to $M_{2}$ respectively.

We consider a sequential bargaining process among the three parties. After deciding to adopt bi-sourcing but before all three parties make any investment, the final good producer $H$ (also called the headquarters as it supplies the headquarters service) may announce whether to negotiate with the internal supplier $M_{1}$ first and then the external supplier $M_{2}$ or the other way around.

Consider the case where the headquarters $H$ first bargains with the internal supplier $M_{1}$ and then with the external supplier $M_{2}$.Using the backward 
induction approach, we first analyze the second stage - the negotiation between $H$ and $M_{2}$ - given that $H$ has successfully concluded its negotiation with $M_{1}$, in which $H$ pays $P_{1}$ to $M_{1}$ and retains $R_{1}-P_{1}$ for itself.

In negotiating with $M_{2}, H$ expects to get $R-P_{1}-P_{2}$ if the trading is carried out but obtains the disagreement option value $R_{1}-P_{1}$ if negotiation breaks down, whereas $M_{2}$ obtains a transfer payment $P_{2}$ from $H$ if trading is conducted and zero otherwise. Given that bargaining is efficient, $H$ and $M_{2}$ reach an agreement on the division of the value of trade $R-R_{1}$, with the external supplier receiving

$$
P_{2}^{*}=(1-\beta)\left(R-R_{1}\right)
$$

and $H$ having $R_{1}-P_{1}+\beta\left(R-R_{1}\right)$.

Next we analyze the first stage - the negotiation between $H$ and $M_{1}$. If there is trade with $M_{1}, H$ secures $R-P_{1}-P_{2}^{*}$ while if there is no trade with $M_{1}, H$ is able to at least gain what he can reap from the scenario of single outsourcing, i.e., $\beta R_{2} \cdot{ }^{5}$ Similarly, $M_{1}$ gets $P_{1}$ with trade and zero otherwise. Thus the Nash bargaining yields a division of the value from trade: $R-P_{2}^{*}-\beta R_{2}=R_{1}+\beta\left(R-R_{1}\right)-\beta R_{2}$ between $H$ and $M_{1}$, with $M_{1}$ receiving

$$
P_{1}^{*}=\left(1-\beta_{I}\right)\left(R_{1}+\beta\left(R-R_{1}\right)-\beta R_{2}\right)
$$

and $H$ has $R-P_{1}^{*}-P_{2}^{*}$.

Under the assumption of perfect foresight, $H$ chooses $h$ to maximize $R-$ $P_{1}^{*}-P_{2}^{*}-w h=\beta \beta_{I} R+\beta_{I}(1-\beta) R_{1}+\beta\left(1-\beta_{I}\right) R_{2}-w h, M_{1}$ chooses $m_{1}$ to maximize $\left(1-\beta_{I}\right)\left[\beta R+(1-\beta) R_{1}-\beta R_{2}\right]-w m_{1}$, and $M_{2}$ chooses $m_{2}$ to maximize $(1-\beta)\left(R-R_{1}\right)-w m_{2}$. Solving these optimization problems, we obtain the total payoff in this scenario of bi-sourcing as

$$
\pi_{B}=\phi_{B}(\mu I)^{\frac{1}{1-\alpha}} Y^{-\frac{\alpha}{1-\alpha}} \theta^{\frac{\alpha}{1-\alpha}}-w f_{B}
$$

where

$$
\begin{aligned}
\phi_{B} & =\alpha^{\frac{\alpha}{1-\alpha}} T^{\frac{\alpha}{1-\alpha} \eta}(1-\beta)^{\frac{\alpha}{1-\alpha}(1-\eta)} w^{\frac{-\alpha}{1-\alpha}}[1-\alpha(\eta T+(1-\eta)(1-\beta))] \\
T & =\beta \beta_{I}+(1-\beta) \beta_{I}\left(\frac{1}{A}\right)^{\alpha(1-\eta)}+\beta\left(1-\beta_{I}\right)\left(1-\frac{1}{A}\right)^{\alpha(1-\eta)}, \\
A & =\left[\frac{1+\beta \beta_{I}-2 \beta}{(1-\beta)\left(1-\beta_{I}\right)}\right]^{\frac{1}{1-\alpha(1-\eta)}}>1 .
\end{aligned}
$$

\footnotetext{
${ }^{5} R-R_{1}$ collapses into $R_{2}$ when the internal supplier $M_{1}$ does not supply any manufactured component, i.e., $m_{1}=0$, and consequently $R_{1}-P_{1}+\beta\left(R-R_{1}\right)$ collapses into $\beta R_{2}$.
} 
Using the same backward induction approach, we can analyze the case where the headquarters $H$ first negotiates with the external supplier $M_{2}$ and then the internal supplier $M_{1}$. But we can show that this sequence of negotiation for bi-sourcing will collapse into single outsourcing. Specifically,

Lemma 1 If the headquarters $H$ negotiates with the external supplier $M_{2}$ before the internal supplier $M_{1}$, the bi-sourcing scenario is reduced to the single outsourcing case.

To put this result in perspective, we can analyze the marginal revenues and marginal costs faced by $M_{1}$ and $M_{2}$. We know that the component supplier who is negotiated later contributes to the total revenue on top of the input made by the component supplier who is negotiated earlier. Given the concavity of the revenue function, the second-to-negotiate-with supplier always contributes less to the total revenue for a given amount of input and in turn claims a lower marginal revenue than the first-to-negotiate-with supplier does. Meanwhile, the external supplier has higher bargaining power and thus claims a larger share of its marginal contribution than the internal supplier does (i.e., $1-\beta>1-\beta_{I}$ ). As a result, when $M_{2}$ is negotiated before $M_{1}, M_{2}$ always gains a higher marginal revenue than $M_{1}$ does. Since $M_{2}$, as the first mover, equates her marginal revenue with the constant marginal cost (common wage rate $w$ ) in equilibrium, $M_{1}$ will encounter a marginal revenue that is always lower than the marginal cost, which will suppress her incentive to make any investment. Consequently, only $M_{2}$, the external component supplier, will make investments to produce the component, which reduces this case of bi-sourcing to single outsourcing.

Since the single sourcing cases have already been investigated in the literature such as Antràs and Helpman (2004), we will focus on the bi-sourcing scenario where the headquarters negotiates with the internal supplier before the external supplier.

\subsection{When is Bi-Sourcing Adopted?}

After obtaining the equilibrium payoffs in single insourcing, single outsourcing and bi-sourcing, we want to know under what circumstances bi-sourcing is chosen by the headquarters as the optimal organizational form.

As in the property-rights theory of the firm, it is assumed that there is competitive supply of component makers ex ante and their outside option can be taken care of through some ex ante transfer payments made by the headquarters. Thus the condition for the headquarters to choose bi-sourcing as the optimal organizational form is that the total payoff from trade is 
highest under bi-sourcing, i.e., $\pi_{B}>\pi_{I}$ and $\pi_{B}>\pi_{O}$. It is clear from equations $(6)$ and (10) that the total payoff $\left(\pi_{i}\right)$ in any scenario is a linear function of the measured productivity $\theta^{\frac{\alpha}{1-\alpha}}$, and it just varies in the slope and the intercept term from one organizational form to another. Since the intercept terms are the negative of the fixed organization costs, it is easy to compare their magnitude by resorting to the assumption in (5). We will focus on the comparison of the slope term, $\phi_{i}$, which can be interpreted as indicating production efficiency.

As a first step, we need to compare the total payoff between single outsourcing and single insourcing, which was studied by Antràs (2003), and Antràs and Helpman (2004).

Lemma 2 There exists a critical point $\eta^{*} \in(0,1)$ such that when $\eta>\eta^{*}$, $\phi_{I}>\phi_{O}$ holds; and when $\eta<\eta^{*}, \phi_{I}<\phi_{O}$ holds.

The intuition of the results comes directly from the property-rights theory of the firm. In our model, the headquarters $(H)$ and the component supplier $(M)$ cooperate in the production process by providing complementary inputs $(h$ and $m$ ). In the production function (3), the factor intensity parameters $\eta$ and $1-\eta$ measure the importance of $h$ and $m$ in the cooperative relationship. When $\eta$ is large so that $\eta>\eta^{*}$ holds, the headquarters' investment is more important to the production process than the component supplier does. In order to encourage the headquarters to invest, it is optimal to give more ownership and control rights to the headquarters. Hence insourcing (integration of component manufacturing by the headquarters) turns out to be better than outsourcing. When $\eta$ is small enough so that $\eta<\eta^{*}$, the component supplier plays a more important role in the cooperative relationship than the headquarters does. As a result, the component supplier should be given more ownership and control rights, and outsourcing becomes more efficient than insourcing.

Now we know the relative optimality between insourcing and outsourcing (i.e., Lemma 2). To find out if bi-sourcing will be chosen as the optimal organizational form, we only need to compare $\phi_{B}$ with $\phi_{I}$ in the headquartersintensive industry (where $\eta>\eta^{*}$ ) and compare $\phi_{B}$ with $\phi_{O}$ in the componentintensive industry (where $\eta<\eta^{*}$ ).

\subsubsection{The headquarters-intensive industry}

First let us look at the headquarters-intensive industry, in which $\phi_{I}>\phi_{O}$ applies. Comparing $\phi_{I}$ of (6) and $\phi_{B}$ of (10), we can show that there exists a $\eta^{* *} \geq \eta^{*}$ such that for all $\eta>\eta^{* *}, \phi_{B}>\phi_{I}$ holds. We thus have the following result: 
Lemma $3 \phi_{B}>\phi_{I}$ holds when $\eta$ is sufficiently high (specifically, $\eta>\eta^{* *}$ ).

From Lemma 3, we know that the production efficiency is the highest under bi-sourcing, followed by insourcing and outsourcing in the headquartersintensive industries $\left(\eta>\eta^{* *}\right)$. But from (5), we know that the fixed cost for bi-sourcing is the highest, followed by insourcing and then outsourcing. Together, we have:

Proposition 1 In the headquarters-intensive industry, the firms with high productivity adopt the bi-sourcing strategy, the firms with low productivity adopt the single outsourcing strategy and those intermediate firms choose the single insourcing strategy.

The results of Lemma 3 and Proposition 1 make intuitive sense. Given the Cobb-Douglas production function specified in equation (3), the provision of headquarters service is important in the headquarters-intensive industry. To encourage the provision of more headquarters service, we need to give the headquarters larger bargaining power and more incentive. In the bi-sourcing scenario, the headquarters has larger bargaining power than she does in single insourcing or outsourcing. This is because, bargaining with both the internal and the external suppliers, the headquarters can make use of the cross threat to strengthen her bargaining power. Specifically, in bargaining with the external supplier, the headquarters can have the in-house production as its default option. Compared with the single outsourcing scenario where the headquarters has zero default option value, the bi-sourcing scenario clearly puts the headquarters at a more advantageous position and mitigates the hold-up threat of the external supplier. Similarly, in negotiating with the internal supplier, the headquarters can effectively curb the problem of lack of incentives on the part of the internal supplier by threatening to resort more to the external supplier if the internal supplier does not perform up to expectation. Hence, in contrast with the single sourcing strategies, bisourcing gives the headquarters a larger share of the total trading surplus and thus higher incentive to produce headquarters service $(h)$, which is crucial in the headquarters-intensive industry. However, bi-sourcing involves the highest fixed organizational costs, and only those firms with productivity lying in the highest interval are able to afford the fixed cost and adopt bisourcing.

Similarly, the choice between insourcing and outsourcing also hinges on the comparison of production efficiency and fixed organizational costs. Although insourcing achieves a higher production efficiency than outsourcing does $\left(\phi_{I}>\phi_{O}\right)$ in the headquarters-intensive industry, insourcing also bears 
a higher fixed organizational cost. That is why only those firms with reasonably high productivity will be able to adopt single insourcing strategy.

\subsubsection{The component-intensive industry}

In the component-intensive industry where $\eta<\eta^{*}$ and $\phi_{I}<\phi_{O}$, single insourcing is dominated by single outsourcing because, compared with outsourcing, insourcing has both higher fixed organization cost $\left(f_{I}>f_{O}\right)$ and lower production efficiency $\left(\phi_{I}<\phi_{O}\right)$. We thus only need to compare single outsourcing and bi-sourcing to see when bi-sourcing will be chosen in the component-intensive industry. Comparing $\phi_{O}$ of (6) and $\phi_{B}$ of (10), we have the following lemma.

Lemma 4 In the component-intensive industry where $\eta<\eta^{*}$ and $\phi_{I}<$ $\phi_{O}, \phi_{B}>\phi_{O}$ always holds.

Combining Lemma 4 with equation (5), we have the following conclusion.

Proposition 2 In the component-intensive industry (i.e., $\eta<\eta^{*}$ ), the firms with high productivity adopt the bi-sourcing strategy while those with low productivity adopt the single outsourcing strategy.

Intuitively in the component-intensive industry, the contribution of an increase in manufactured component to the total output is particularly large. It can be shown that bi-sourcing generates a larger total amount of manufactured component than single outsourcing does. Why is this the case? On the one hand, compared with outsourcing, bi-sourcing that combines integration with outsourcing can mitigate the holdup problem in contracting with the external supplier; but on the other hand it also reduces the incentive of the external supplier as the latter's share of ownership and control over the assets for component manufacturing has diminished. Fortunately it turns out that the internal component supplier has sufficiently large incentive for component production so as to overcome the negative effect of the diminishing incentive of the external supplier. Moreover, with the reduction in the holdup problem, the headquarters has more incentive to make investment for headquarters service under bi-sourcing than under outsourcing. Both the internal and external component suppliers gain from the increase in the headquarters service owing to the complementarity of inputs in the cooperative production process. As a consequence, the total supply of manufactured component has further increased.

To summarize, we have shown that the bi-sourcing strategy yields the highest production efficiency in both the headquarters-intensive industry and 
the component-intensive industry. This, combined with the difference in the fixed organizational costs leads to the result that the higher-productivity firms adopt the bi-sourcing strategy because only those firms can overcome the extra fixed cost and enjoy the benefit of lower variable cost in the bisourcing scenario.

\section{Bi-sourcing in the Global Economy}

Now we turn to the open-economy case. Suppose that the world consists of two countries - the high-waged North and the low-waged South. Let $w^{N}$ denote the wage rate in the North and $w^{S}$ denote the wage rate in the South where $t \equiv \frac{w^{N}}{w^{S}}>1$. For simplicity of analysis, it is assumed that the headquarters service $(h)$ can only be produced in the North with one unit of labor generating one unit of $h$, whereas the manufactured component $(m)$ can be produced either in the North or in the South with one unit of labor producing one unit of $m$ in either location. It is further assumed that the relative bargaining power between the headquarters and the suppliers remains constant across the locations (See Grossman, Helpman and Szeidle (2004) for making the same assumption.)

In the open-economy case, the headquarters needs to make both location and organization choices. There are altogether eight possibilities: (i) Single insourcing in the North, (ii) single outsourcing in the North, (iii) bi-sourcing in the North, (iv) single insourcing in the South, (v) single outsourcing in the South, (vi) bi-sourcing in the South, (vii) bi-sourcing with insourcing in the North and outsourcing in the South, and (viii) bi-sourcing with insourcing in the South and outsourcing in the North. The comparison of (i), (ii) and (iii) is just like what we had in the closed-economy setting, and the same is true for the comparison of (iv), (v), and (vi). The intuition we get from the closed-economy setting is that bi-sourcing has higher production efficiency but involves higher fixed cost, and so it is the high-productivity firms that choose bi-sourcing in both the headquarters-intensive industry or the components-intensive industry. Meanwhile, the comparison of single sourcing strategies in the global economy, i.e., (i), (ii), (iv) and (v), has been studied in the literature (see Antràs and Helpman, 2004). Thus, in this section, we would like to focus on the bi-sourcing strategies in the global economy, i.e., (iii), (vi), (vii), and (viii). For ease of exposition, we come up with simple notations for the four possible bi-sourcing cases, both insourcing and outsourcing in the North by $N N$, both insourcing and outsourcing in the South by $S S$, insourcing in the North and outsourcing in the South by $N S$, and insourcing in the South and outsourcing in the North by $S N$, with the 
first letter denoting the location of insourcing and the second letter denoting the location of outsourcing.

As in the closed-economy setting, the choice among the four bi-sourcing arrangements depends on the interplay between the organizational fixed cost and the production efficiency. One may argue that even the four bi-sourcing arrangements could involve different organizational fixed costs. From the analysis in the closed-economy setting, however, we know that the organizational fixed costs have predictable impacts on the organizational choice (the higher-productivity firms versus lower-productivity firms arguments). Thus in this section we would like to focus on the production efficiency as the key criterion for the optimal bi-sourcing strategy. Indeed, the insights from the property-rights theory of the firm are about the impacts of organizational choice on the investment incentive and production efficiency.

In what follows, we first compare $N N$ with $S S$ to illustrate the impact of the difference in wage rate between the North and the South - the cost difference effect (Section 4.1). Next, in Section 4.2, we compare $S N, N S$, and $S S$ to highlight how the location choice affects the relative bargaining power of the external and internal suppliers and consequently their investment incentive - the balancing effect. Both the cost difference effect and the balancing effect are crucial to the production efficiency of bi-sourcing strategies in the open-economy setting. Optimal bi-sourcing strategies will be derived for the case of strong internal supplier and weak external supplier (Section 4.3), and for the case of weak internal supplier and strong external supplier (Section 4.4). Before embarking on the analysis, we list the first-order conditions for the headquarters, the internal supplier and the external supplier respectively

$$
\left\{\begin{array}{c}
\alpha \mu I Y^{-\alpha} \theta^{\alpha}\left[\frac{h}{\eta}\right]^{\alpha \eta-1}\left[\frac{m_{1}+m_{2}}{1-\eta}\right]^{\alpha(1-\eta)} T(x)=w^{N} \\
\alpha\left(1-\beta_{I}\right) \mu I Y^{-\alpha} \theta^{\alpha}\left[\frac{h}{\eta}\right]^{\alpha \eta}\left\{\beta\left[\frac{m_{1}+m_{2}}{1-\eta}\right]^{\alpha(1-\eta)-1}+(1-\beta)\left[\frac{m_{1}}{1-\eta}\right]^{\alpha(1-\eta)-1}\right\}=w^{i} \\
\alpha(1-\beta) \mu I Y^{-\alpha} \theta^{\alpha}\left[\frac{h}{\eta}\right]^{\alpha \eta}\left[\frac{m_{1}+m_{2}}{1-\eta}\right]^{\alpha(1-\eta)-1}=w^{i}
\end{array}\right.
$$

where $i \in\{N, S\}, T(x)=\beta \beta_{I}+(1-\beta) \beta_{I}(x)^{\alpha(1-\eta)}+\beta\left(1-\beta_{I}\right)(1-x)^{\alpha(1-\eta)}$ and $x=\frac{m_{1}}{m_{1}+m_{2}}$. Here $x$ is the ratio of manufactured component made by the internal supplier. It reflects the relative contribution or bargaining power of the internal and external suppliers to the total output and total profits, and it will play an important role in the following analysis and discussion.

\subsection{Comparing $N N$ and $S S$ : the Cost Difference Effect}

We begin with the comparison between $N N$ and $S S$. As both the internal and external suppliers in these two strategies are located in the same country, 
it allows us to explore the impact of the difference in wage rate between the South and the North (or the cost difference effect).

We can derive the total payoffs under $N N$ and $S S$ strategies as:

$$
\pi^{N N}=\phi^{N N}(\mu I)^{\frac{1}{1-\alpha}} Y^{-\frac{\alpha}{1-\alpha}} \theta^{\frac{\alpha}{1-\alpha}}-w^{N} f^{N N}
$$

where

$$
\begin{aligned}
\phi^{N N} & =\alpha^{\frac{\alpha}{1-\alpha}} T^{\frac{\alpha}{1-\alpha} \eta}(1-\beta)^{\frac{\alpha}{1-\alpha}(1-\eta)}\left(w^{N}\right)^{\frac{-\alpha}{1-\alpha}}[1-\alpha(\eta T+(1-\eta)(1-\beta))] \\
T & =\beta \beta_{I}+(1-\beta) \beta_{I}\left(\frac{1}{A}\right)^{\alpha(1-\eta)}+\beta\left(1-\beta_{I}\right)\left(1-\frac{1}{A}\right)^{\alpha(1-\eta)} \\
A & =\left[\frac{1+\beta \beta_{I}-2 \beta}{(1-\beta)\left(1-\beta_{I}\right)}\right]^{\frac{1}{1-\alpha(1-\eta)}}
\end{aligned}
$$

and

$$
\pi^{S S}=\phi^{S S}(\mu I)^{\frac{1}{1-\alpha}} Y^{-\frac{\alpha}{1-\alpha}} \theta^{\frac{\alpha}{1-\alpha}}-w^{N} f^{S S}
$$

where

$$
\phi^{S S}=\alpha^{\frac{\alpha}{1-\alpha}} T^{\frac{\alpha}{1-\alpha} \eta}[t(1-\beta)]^{\frac{\alpha}{1-\alpha}(1-\eta)}\left(w^{N}\right)^{\frac{-\alpha}{1-\alpha}}[1-\alpha(\eta T+(1-\eta)(1-\beta))]
$$

and $T$ and $A$ are defined as in (12).

Dividing $\phi^{N N}$ by $\phi^{S S}$, we obtain

$$
\frac{\phi^{N N}}{\phi^{S S}}=t^{\frac{-\alpha}{1-\alpha}(1-\eta)}<1
$$

This inequality holds because $t>1$. The result of $\phi^{N N}<\phi^{S S}$ shows clearly that the cost advantage of the South over the North enhances the production efficiency when both the internal and the external suppliers are located in the South. We thus derive the following conclusion.

Proposition 3 As the wage rate in the South is lower than that in the North, putting both component suppliers in the South (SS) gains a higher production efficiency than putting both in the North (NN).

The case of $S S$ is quite similar to that of $N N$, except that both the internal and external suppliers in $S S$ have lower marginal cost due to the lower wage rate in the South. It follows that the suppliers in $S S$ have stronger incentive to invest than those in $N N$, which leads to more component supply. This in turn induces the headquarters to increase the supply of headquarters service due to the complementarity effect in production, which further increases the incentive of the component suppliers to invest. This chain effect leads to a higher level of production efficiency in $S S$ than in $N N$. 


\subsection{Comparing $S S, N S$, and $S N$ : the Balancing Effect}

Next we compare $S S, N S$ and $S N$, with the aim of examining how the location choice for the bi-sourcing strategy affects the relative bargaining power of the external and internal suppliers and consequently their investment incentive - henceforth called the balancing effect. We first derive the production efficiency $(\phi)$ under $N S$ and $S N$ as

$$
\phi^{N S}=\alpha^{\frac{\alpha}{1-\alpha}}\left(T^{N S}\right)^{\frac{\alpha}{1-\alpha} \eta}[t(1-\beta)]^{\frac{\alpha}{1-\alpha}(1-\eta)}\left(w^{N}\right)^{\frac{-\alpha}{1-\alpha}}\left[1-\alpha\left(\eta T^{N S}+(1-\eta)(1-\beta)\left(\frac{t+B-1}{B}\right)\right]\right.
$$

where

$$
\begin{aligned}
T^{N S} & =\beta \beta_{I}+(1-\beta) \beta_{I}\left(\frac{1}{B}\right)^{\alpha(1-\eta)}+\beta\left(1-\beta_{I}\right)\left(1-\frac{1}{B}\right)^{\alpha(1-\eta)} \\
B & =\left[\frac{t(1-\beta)-\beta\left(1-\beta_{I}\right)}{(1-\beta)\left(1-\beta_{I}\right)}\right]^{\frac{1}{1-\alpha(1-\eta)}}>1
\end{aligned}
$$

and

$\phi^{S N}=\alpha^{\frac{\alpha}{1-\alpha}}\left(T^{S N}\right)^{\frac{\alpha}{1-\alpha} \eta}(1-\beta)^{\frac{\alpha}{1-\alpha}(1-\eta)}\left(w^{N}\right)^{\frac{-\alpha}{1-\alpha}}\left[1-\alpha\left(\eta T+(1-\eta)(1-\beta) \frac{t C-t+1}{t C}\right)\right]$

where

$$
\begin{aligned}
T^{S N} & =\beta \beta_{I}+(1-\beta) \beta_{I}\left(\frac{1}{C}\right)^{\alpha(1-\eta)}+\beta\left(1-\beta_{I}\right)\left(1-\frac{1}{C}\right)^{\alpha(1-\eta)} \\
C & =\left[\frac{(1-\beta)-t \beta\left(1-\beta_{I}\right)}{t(1-\beta)\left(1-\beta_{I}\right)}\right]^{\frac{1}{1-\alpha(1-\eta)}}>1
\end{aligned}
$$

It is noteworthy that in order to have the $S N$ case, the wage difference between the South and the North cannot be too large, i.e., $t<\frac{1-\beta}{1-\beta_{I}}$, otherwise the $S N$ case collapses to single insourcing in the South.

Comparing (13), (15) and (16), we find that $T, T^{N S}$ and $T^{S N}$ share the same functional form $T(x)$ of (11), where $x$ equals $\frac{1}{A}, \frac{1}{B}$ and $\frac{1}{C}$ for $T, T^{N S}$ and $T^{S N}$ respectively. Recall that $x$ is the ratio of manufactured component made by the internal supplier, reflecting the relative bargaining power or the relative contribution of the internal supplier versus the external supplier to the total output and payoff. As shown in (13), (15) and (16), $x$ can be adjusted by the location choice of the bi-sourcing strategy.

Differentiating $T(x)$ with respect to $x$, we can obtain the optimal $x^{*}$ that maximizes $T$ as

$$
x^{*}=x\left(\beta_{I}, \beta, \alpha, \eta\right) \text {. }
$$


We call $x^{*}$ as the ideal $x$ achieving the optimal balancing of the relative bargaining power between the internal and external suppliers. When $x<x^{*}$, $T$ is increasing in $x$; when $x>x^{*}, T$ is decreasing in $x$.

When $x^{*}=\frac{1}{A}$, then $S S$ achieves the optimal balancing effect. Note also that $S S$ has larger cost advantages than $N N, N S$ and $S N$ do. Together, we can show that $S S$ has higher production efficiency than $N S$ and $S N$ do.

Proposition 4 When locating both the internal and external suppliers in the South achieves the optimal balancing effect (i.e., $x^{*}=\frac{1}{A}$ ), then $S S$ has higher production efficiency than $N S$ or $S N$ do.

Substituting $x^{*}=\frac{1}{A}$ into (17), we can obtain an optimal level of $\beta_{I}^{*}$ :

$$
\beta_{I}^{*}=f(\beta, \alpha, \eta) .
$$

When $\beta_{I}<\beta_{I}^{*}, \frac{1}{A}>x^{*}$; and when $\beta_{I}>\beta_{I}^{*}, \frac{1}{A}<x^{*}$.

It can be shown that $\frac{1}{B}<\frac{1}{A}<\frac{1}{C}$. When $\beta_{I}<\beta_{I}^{*}, \frac{1}{C}>\frac{1}{A}>x^{*}$ holds and $S N$ (corresponding to $\frac{1}{C}$ ) is clearly inferior to $S S$ (corresponding to $\frac{1}{4}$ ) in terms of the balancing effect. However, $N S$ (corresponding to $\frac{1}{B}$ ) may allow the headquarters to achieve a more satisfactory balancing effect than $S S$. When the reverse situation occurs, i.e., $\beta_{I}>\beta_{I}^{*}$, we have $x^{*}>\frac{1}{A}>\frac{1}{B}$, which means that $N S$ is inferior to $S S$. But it is likely that the $S N$ scenario may enable the headquarters to achieve a better balancing effect than $S S$ as $\frac{1}{C}$ is larger than $\frac{1}{A}$ and is likely to be closer to $x^{*}$.

The intuition goes like this. When $\beta_{I}$ is sufficiently low (or $\beta_{I}<\beta_{I}^{*}$, henceforth called "strong internal supplier and weak external supplier" as will be analyzed in Section 4.3), the internal supplier has very high incentive to produce component. This could pose such a big threat to the external supplier in her bilateral negotiation with the headquarters that the external supplier's investments in component manufacturing would be deterred, which in turn weakens the headquarters' bargaining power in negotiation with the internal supplier. This destroys the balance of the relative bargaining power between the internal and the external suppliers. To correct this imbalance, the headquarters can move insourcing to the North so as to force the internal supplier to bear a high labor cost, reducing its incentive for component production and thus mitigating its threat to the external supplier. Conversely, when $\beta_{I}$ is sufficiently high (or $\beta_{I}>\beta_{I}^{*}$, henceforth called "strong external supplier and weak internal supplier" as will be analyzed in Section 4.4), the internal supplier has rather weak bargaining power, while the external supplier becomes too powerful. To balance the relative bargaining power between the internal and external suppliers, the headquarters can weaken the 
strength of the external supplier by locating it in the North to bear a high labor cost.

In summary, it is the consideration of the balancing effect that may prompt the headquarters to separately locate the internal and external suppliers.

\subsection{Strong Internal Supplier and Weak External Sup- plier}

The analysis of Section 4.2 suggests that, under the circumstance of strong internal supplier and weak external supplier (i.e., $\beta_{I}<\beta_{I}^{*}$ ), $S S$ has a higher level of production efficiency than $S N$ for the former is better than the latter in terms of both the cost difference effect and the balancing effect. Thus in this scenario we only need to compare $N S$ with $S S$ to find out which bi-sourcing arrangement has the highest production efficiency.

Start from the situation that the difference in wage rates between the North and the South is quite small (i.e., $t$ is close to 1 ). If the headquarters moves insourcing to the North, it will generate two positive and one negative effects on the component production. On the positive side, firstly, the relative bargaining power of the internal supplier is whittled down and that of the headquarters is improved. As a result, the headquarters will supply more headquarters service, which in turn stimulates the supply of manufactured component. Secondly, it will transfer much of the component supply from insourcing to outsourcing. Since the external supplier has higher incentive and lower cost than the internal supplier does, this transfer may enhance the total component supply. On the negative side, the production of the internal supplier will be largely reduced as it faces a high labor cost. Overall, the positive factors dominate the the negative one, leading the total component supply to increase following the location shift of the internal supplier from the South to the North.

When the wage rate difference (i.e. $t$ ) increases, it may further reduce the relative bargaining power of the internal supplier and improve that of the headquarters, which causes the total component production to increase. The continuous increase in $t$ will eventually reach a point where the headquarters attains the most satisfactory balancing effect, i.e., $x^{*}=\frac{1}{B}$. Beyond that point, the increase in the wage rate difference will reverse the relative situation of the two suppliers, i.e., the internal supplier becomes too weak and the external supplier becomes too powerful, which is unfavorable to the headquarters. Under such a situation, transferring insourcing from the North to the South (from $N S$ to $S S$ ) will enhance the relative bargaining power of 
the internal supplier, which will in turn improve the headquarters' strength in negotiating with the external supplier and increase its incentive to provide the headquarters service. Moreover, the investment on component production from the internal supplier will increase as it now faces a low labor input cost. So, the location shift of the internal supplier from the North to the South will result in more supply of both the component and the headquarters service, and thus produces a higher production efficiency under $S S$ than under $N S$.

From the above analysis, we have the following result.

Proposition 5 In the case of strong internal supplier and weak external supplier (i.e., $\beta_{I}<\beta_{I}^{*}$ ): (i) locating insourcing in the North and outsourcing in the South (NS) generates the highest production efficiency so long as the wage difference between the two countries is small; (ii) otherwise, locating both insourcing and outsourcing in the South yields the highest production efficiency.

\subsection{Weak Internal Supplier and Strong External Sup- plier}

Under this circumstance, since the internal supplier has too weak bargaining power relative to the external supplier, moving the internal supplier from the South to the North (or moving from $S S$ to $N S$ ) cannot help balance the relative bargaining power between the two suppliers. In addition, $N S$ has a cost disadvantage as compared with $S S$. Thus $N S$ is clearly dominated by $S S$, and we will focus on the comparison between $S N$ and $S S$ to find out which bi-sourcing arrangement has the highest production efficiency.

Since the internal supplier is too weak, moving outsourcing to the North (i.e., moving from $S S$ to $S N$ ) will diminish the relative bargaining power of the external supplier and increase that of the internal supplier. This enhances the incentive of the internal supplier to invest, which in turn improves the bargaining strength of the headquarters and increases the provision of headquarters service. However, there also exists a negative effect. The external supplier will reduce its investment as it loses its cost advantage and bears a high labor cost in going from $S S$ to $S N$. So the net effect on the total component production depends on two competing forces. On the one hand, the increase in the provision of headquarters service will boost component production by both the internal and external suppliers; on the other hand, the changing incentive structure causes the external supplier to lower component production but the internal supplier to raise. It turns out that 
the increase in the investment by the internal supplier can hardly cover the large drop in the investment by the external supplier. Even in the situation with low wage difference, transferring outsourcing to the North is inferior to putting both suppliers in the South in terms of component manufacturing. In equilibrium, the latter negative effect dominates the former positive effect.

When the wage difference increases, the situation becomes even worse as the drop in the external supplier's component production exceeds the increment in the internal supplier's component production to a larger and larger degree. The further increase in the wage difference will finally either drive out the external supplier reducing $S N$ to single insourcing in the South. We therefore have the following conclusion.

Proposition 6 In the case of weak internal supplier and strong external supplier (i.e., $\beta_{I}>\beta_{I}^{*}$ ), locating both suppliers in the South generates the highest production efficiency regardless of wage difference between the South and the North.

\subsection{Some Implications for World Trade Pattern}

Our study of bi-sourcing in the global economy can help us understand not only the organizational and location choices of multinational enterprises in carrying out bi-sourcing but also some of the new trends in international trade in recent decades. Three aspects of world trade pattern are noteworthy.

Firstly, vertical specialization is shown to have made important contributions to the spectacular growth in world trade. Since the early 1960s, the share of global manufacturing export in world GDP has risen by a factor of 3.4 (World Trade Organization, 2000). However, the world tariffs have dropped by only 11 percent during this period, which can hardly account fully for the trade explosion. Some studies show that vertical specialization, i.e., the increasing interconnections of production processes in a sequential and vertical trading chain stretching across many countries with each country specializing in particular stages of a good's production sequence, has grown about 30 percent and accounts for about one-third of the growth in trade in the last 20-30 years (Hummels, Rapoport and Yi, 1998; Hummels, Ishii and Yi, 2001; Yi, 2003).

Secondly, intrafirm trade becomes a significant component of world trade. It is reported that around one third of world trade is within-firm trade (Antràs, 2003). It is also estimated that intrafirm trade accounted for more than one third of US exports of goods and for more than two fifths of US imports of goods (Zeile, 1997). 
Lastly, there is growing evidence on the complementarity between foreign direct investment and trade. Eaton and Tamura (1994) find that, for Japan and the US, there is a large and positive relationship between outward FDI and imports as well as exports. Fontagne and Pajot (1997) report that one dollar of US investment abroad is associated with $\$ 2.6$ and $\$ 2.3$ additional, bilateral exports and imports within industries respectively. Similarly, each one dollar of the US FDI stock abroad is associated with an additional bilateral imports and exports of 1.3 dollars and 70 cents respectively.

According to our analysis, locating both internal and external suppliers in the South $(S S)$ is oftentimes the optimal bi-sourcing strategy adopted by the multinational enterprise in our model. This strategy involves intrafirm cross-border trade (mainly imports of components) between the headquarters and the internal supplier; it also contains the headquarters' imports of intermediate goods from the external supplier. Clearly, the existence of the $S S$ bi-sourcing strategy with internal and external component suppliers located in the South contributes to the growth in vertical specialization and intrafirm trade, which in turn constitute significant sources of world trade growth.

The $S S$ case of bi-sourcing strategy also bundles together foreign direct investment and international trade. By insourcing from an internal component manufacturer on the foreign soil (the South), the $S S$ bi-sourcing strategy involves foreign direct investment. By outsourcing from a foreign external supplier, it also contains trade in, particularly imports of, intermediate goods. The emergence of the $S S$ bi-sourcing strategy clearly contributes to the complementarity between foreign direct investment and international trade.

Moreover, in our model, the relative strength index $x=\frac{m_{1}}{m_{1}+m_{2}}$ reflects the proportion of intrafirm trade between the headquarters and the internal supplier $\left(m_{1}\right)$ in total intermediate goods trade $\left(m_{1}+m_{2}\right)$. In our framework, it can be used to approximate the share of intrafirm trade in total trade. We can easily see that the $x$ is increasing in the relative importance of the headquarters service in total output and revenue functions $(\eta)$, that is, $\frac{\partial x}{\partial \eta}>0$. This implies that the intrafirm trade will account for a larger proportion of international trade in more headquarters-intensive industries. This is consistent with one stylized fact - US intrafirm trade is heavily concentrated in capital-intensive industries (Antràs, 2003) because US-based multinational enterprises usually place capital-intensive production at home while move labor-intensive industries to the low-waged South. 


\section{Concluding Remarks}

In this paper, we extend the framework of Antràs and Helpman (2004) to study the growing business strategy of bi-sourcing, that is, firms adopt insourcing and outsourcing simultaneously in acquiring the same intermediate inputs. We show that in conducting bi-sourcing firms can take advantage of the cross threat effect in trilateral negotiation to mitigate the inherent problems of both insourcing and outsourcing. On the one hand, the firm can use the internal component supplier as a default option to minimize the potential efficiency losses from the holdup problem of the external supplier. On the other hand, the external supplier as an alternative source of component provision can force the internal supplier to make relationship-specific investments and improve productivity, which mitigates the lack of incentive problem on the part of the internal supplier. Given that bi-sourcing contains the fixed costs of both insourcing and outsourcing, our model predicts that only the most productive firms will be able to adopt bi-sourcing strategy.

When multinational enterprises conduct bi-sourcing in the global economy, they choose the location of internal and external suppliers, i.e., in the high-waged North or low-waged South. We identify two factors. One is the cost difference between the North and South, and the other is the balancing effect between the internal and external suppliers. Our analysis shows that locating both suppliers in the low-cost South is most likely to be chosen for its highest production efficiency. In addition, multinational enterprises may also choose to locate the internal supplier in the North and the external supplier in the South to achieve an optimal balancing effect. We demonstrate that our results are consistent with some important facts in world trade pattern, and they help us understand the growing importance of vertical specialization, intrafirm trade and complementarity between trade and foreign direct investments.

\section{References}

Aghion, Phillipe and Jean Tirole (1997) "Formal and Real Authority in Organizations", Journal of Political Economy 105 (1), 1-29.

Anton, James J. and Dennis A. Yao (1987) "Second Sourcing and the Experience Curve: Price Competition in Defence Procurement", RAND Journal of Economics 18 (1), 57-76.

Antràs, Pol (2003) "Firms, Contracts, and Trade Structure", Quarterly Journal of Economics 118 (4), 1375-1418.

Antràs, Pol (2005) "Property Rights and the International Organization of Production", American Economic Review (Papers and Proceedings) 95 (2), forthcoming. 
Antràs, Pol and Elhanan Helpman (2004) "Global Sourcing", Journal of Political Economy 112 (3), 552-580.

Antràs, Pol, Luis Garicano and Esteban Rossi-Hansberg (2006) "Offshoring in a Knowledge Economy", Quarterly Journal of Economics, forthcoming. Carey, Susan and Alex Frangos (2005) "Facing Cost Pressures, U.S. Airlines Outsource Crucial Safety Functions", Asian Wall Street Journal, January 24, page 1.

Cohen, Linda and Allie Young (2006). Multisourcing: Moving Beyond Outsourcing to Achieve Growth and Agility, Boston, Mass. : Harvard Business School Press.

Dick, Andrew R. (1990) "An Efficiency Explanation for Why Firms Second Sourcing", Working paper No. 602, University of California, Los Angeles.

Eaton, Jonathan and Akiko Tamura (1994) "Bilateralism and Regionalism in Japanese and US Trade and Direct Foreign Investment Patterns", Journal of the Japanese and International Economics 8, 478-510.

Farrell, Joseph and Nancy T. Gallini (1988) "Second-sourcing as a Commitment: Monopoly Incentives to Attract Competition", Quarterly Journal of Economics 103 (4), 673-694.

Fontagne, Lionel and Michael Pajot (1997) "How Foreign Direct Investment Affects International Trade and Competitiveness: an Empirical Assessment", CEPII working paper.

Grossman, Gene M. and Elhanan Helpman (2002) "Integration versus Outsourcing in Industry Equilibrium", Quarterly Journal of Economics 117 (1), 85-120.

Grossman, Gene M. and Elhanan Helpman (2004) "Managerial Incentives and International Organization of Production", Journal of International Economics 63 (2), 237-262.

Grossman, Gene M. and Elhanan Helpman (2005) "Outsourcing in a Global Economy", Review of Economic Studies 72 (1), 135-160.

Grossman, Gene M., Elhanan Helpman and Adam Szeidle (2005) "Complementarities between Outsourcing and Foreign Sourcing", American Economic Review (Papers and Proceedings) 95 (2), forthcoming.

Grossman, Sanford and Oliver Hart (1986) "Costs and Benefits of Ownership: A Theory of Vertical and Lateral Integration", Journal of Political Economy 94 (4), 691-719.

Hart, Oliver (1995) Firms, Contracts, and Market Structure, New York: Oxford University Press.

Hart, Oliver and John Moore (1990) "Property Rights and the Nature of the Firm", Journal of Political Economy 98 (6), 1119-1158.

Holmström, Bengt and Paul Milgrom (1991) "Multitask Principal-Agent Analysis: Incentives Contracts, Asset Ownership and Job Design", Journal 
of Law, Economics and Organization 7, 24-52.

Holmström, Bengt and Paul Milgrom (1994) "The Firm as an Incentive System", American Economic Review 84 (4), 972-991.

Hummels, David, Jun Ishii and Kei-Mu Yi (2001) "The Nature and Growth of Vertical Specialization in World Trade", Journal of International Economics 54, 74-96

Hummels, David, Dana Rapoport and Kei-Mu Yi (1998). "Vertical Specialization and the Changing Nature of World Trade", Federal Reserve Bank New York Economic Policy Review 4, 79-99

Kerschbamer, Rudolf and Yanni Tournas (2003) "In-house Competition, Organizational Slack, and the Business Cycle", European Economic Review 47, 505-520.

Marin, Dalia and Thierry Verdier (2003) "Globalization and the Empowerment of Talent", CEPR Discussion Paper No. 4129.

Melitz, Marc. (2003) "The Impact of Trade on Intra-industry Reallocations and Aggregate Industry Productivity", Econometrica 71, 1695-1725.

McLaren, John. (1999) "'Globalization' and Vertical Structure", American Economic Review 90, 1239-1254

Nokia (2003) Annual Report.

Puga, Diego and Daniel Trefler (2002) "Knowledge Creation and Control in Organizations", NBER Working Paper No. 9121.

Riordan, Michael H. and David E.M. Sappington (1989) "Second Sourcing", RAND Journal of Economics 20 (1), 41-58.

Shepard, Andrea (1987) "Licensing to Enhance Demand for New Technologies", RAND Journal of Economics 18 (3), 360-368.

Spencer, Barbara J. (2005) "International Outsourcing and Incomplete Contracts", Canadian Journal of Economics 38, 1107-1135

Williamson, Oliver E. (1975) Markets and Hierarchies: Analysis and Antitrust Implications, New York: The Free Press.

Williamson, Oliver E. (1985) The Economic Institutions of Capitalism, New York: The Free Press.

World Trade Organization (2000) International Trade Statistics. Geneva: World Trade Organization.

Yi, Kei-mu (2003) "Can Vertical Specialization Explain the Growth of World Trade", Journal of Political Economy 111(1), 52-102.

Zeile, William J. (1997) "U.S. Intrafirm Trade in Goods", Survey of Current Business 77(2), 23-38. 


\section{Appendix}

\section{Derivation of (6)}

As $M$ chooses an amount of $m$ to maximize $\left(1-\beta_{k}\right) R-w m$ and $H$ provides an amount of headquarters service $h$ to maximize $\beta_{k} R-w h$, the first order conditions for the profit maximization problems are

$$
\left\{\begin{array}{c}
\alpha\left(1-\beta_{k}\right) \mu I Y^{-\alpha} \theta^{\alpha}\left[\frac{h}{\eta}\right]^{\alpha \eta}\left[\frac{m}{1-\eta}\right]^{\alpha(1-\eta)-1}=w \\
\alpha \beta_{k} \mu I Y^{-\alpha} \theta^{\alpha}\left[\frac{h}{\eta}\right]^{\alpha \eta-1}\left[\frac{m}{1-\eta}\right]^{\alpha(1-\eta)}=w
\end{array}\right.
$$

which yields the equilibrium value of the two inputs as

$$
\left\{\begin{array}{l}
h_{k}=\eta \alpha^{\frac{1}{1-\alpha}}(\mu I)^{\frac{1}{1-\alpha}} Y^{-\frac{\alpha}{1-\alpha}} \theta^{\frac{\alpha}{1-\alpha}}\left(\beta_{k}\right)^{\frac{\alpha}{1-\alpha} \eta+1}\left(1-\beta_{k}\right)^{\frac{\alpha}{1-\alpha}(1-\eta)} w^{-\frac{\alpha}{1-\alpha}} \\
m_{k}=\eta \alpha^{\frac{1}{1-\alpha}}(\mu I)^{\frac{1}{1-\alpha}} Y^{-\frac{\alpha}{1-\alpha}} \theta^{\frac{\alpha}{1-\alpha}}\left(\beta_{k}\right)^{\frac{\alpha}{1-\alpha} \eta}\left(1-\beta_{k}\right)^{\frac{\alpha}{1-\alpha}(1-\eta)+1} w^{-\frac{\alpha}{1-\alpha}}
\end{array}\right.
$$

The total profits are calculated as

$$
\begin{aligned}
\pi_{k}= & R-w h_{k}-w m_{k}-w f_{k} \\
= & \alpha^{\frac{\alpha}{1-\alpha}}(\mu I)^{\frac{1}{1-\alpha}} Y^{-\frac{\alpha}{1-\alpha}} \theta^{\frac{\alpha}{1-\alpha}}\left(\beta_{k}\right)^{\frac{\alpha}{1-\alpha} \eta}\left(1-\beta_{k}\right)^{\frac{\alpha}{1-\alpha}(1-\eta)} w^{-\frac{\alpha}{1-\alpha}}\left[1-\alpha\left(\beta_{k} \eta\right.\right. \\
& \left.\left.+\left(1-\beta_{k}\right)(1-\eta)\right)\right]-w f_{k} \\
= & \phi_{k}(\mu I)^{\frac{1}{1-\alpha}} Y^{-\frac{\alpha}{1-\alpha}} \theta^{\frac{\alpha}{1-\alpha}}-w f_{k}
\end{aligned}
$$

which gives Equation (6).

\section{Derivation of (10)}

The first order conditions for the headquarters $(H)$, the internal supplier $\left(M_{1}\right)$ and the external supplier $\left(M_{2}\right)$ are

$$
\left\{\begin{aligned}
w= & \alpha \mu I Y^{-\alpha} \theta^{\alpha}\left[\frac{h}{\eta}\right]^{\alpha \eta-1} \\
& \left\{\beta \beta_{I}\left[\frac{m_{1}+m_{2}}{1-\eta}\right]^{\alpha(1-\eta)}+(1-\beta) \beta_{I}\left[\frac{m_{1}}{1-\eta}\right]^{\alpha(1-\eta)}+\beta\left(1-\beta_{I}\right)\left[\frac{m_{2}}{1-\eta}\right]^{\alpha(1-\eta)}\right\} \\
w= & \alpha\left(1-\beta_{I}\right) \mu I Y^{-\alpha} \theta^{\alpha}\left[\frac{h}{\eta}\right]^{\alpha \eta} \\
& \left\{\beta\left[\frac{m_{1}+m_{2}}{1-\eta}\right]^{\alpha(1-\eta)-1}+(1-\beta)\left[\frac{m_{1}}{1-\eta}\right]^{\alpha(1-\eta)-1}\right\} \\
w= & \alpha(1-\beta) \mu I Y^{-\alpha} \theta^{\alpha}\left[\frac{h}{\eta}\right]^{\alpha \eta}\left[\frac{m_{1}+m_{2}}{1-\eta}\right]^{\alpha(1-\eta)-1}
\end{aligned}\right.
$$


Dividing the second equation by the last one, we get

$$
\begin{aligned}
(1-\beta)\left[\frac{m_{1}+m_{2}}{1-\eta}\right]^{\alpha(1-\eta)-1}= & \left(1-\beta_{I}\right) \beta\left[\frac{m_{1}+m_{2}}{1-\eta}\right]^{\alpha(1-\eta)-1} \\
& +(1-\beta)\left(1-\beta_{I}\right)\left[\frac{m_{1}}{1-\eta}\right]^{\alpha(1-\eta)-1} \\
\Rightarrow \quad & \frac{m_{1}+m_{2}}{m_{1}}=\left[\frac{1+\beta \beta_{I}-2 \beta}{(1-\beta)\left(1-\beta_{I}\right)}\right]^{\frac{1}{1-\alpha(1-\eta)}} \equiv A>1
\end{aligned}
$$

and $m_{2}=(A-1) m_{1}$.

Substitute (20) back into (19), we get

$$
\left\{\begin{aligned}
w= & \alpha \mu I Y^{-\alpha} \theta^{\alpha}\left[\frac{h}{\eta}\right]^{\alpha \eta-1}\left[\frac{m_{1}+m_{2}}{1-\eta}\right]^{\alpha(1-\eta)}\left[\beta \beta_{I}+(1-\beta) \beta_{I} A^{-\alpha(1-\eta)}\right. \\
& \left.+\beta\left(1-\beta_{I}\right)\left(\frac{A-1}{A}\right)^{\alpha(1-\eta)}\right] \\
w= & \alpha(1-\beta) \mu I Y^{-\alpha} \theta^{\alpha}\left[\frac{h}{\eta}\right]^{\alpha \eta}\left[\frac{m_{1}+m_{2}}{1-\eta}\right]^{\alpha(1-\eta)-1}
\end{aligned}\right.
$$

Divide the second equation by the first one, we can get

$$
\frac{\frac{h}{\eta}}{\frac{m_{1}+m_{2}}{1-\eta}}=\frac{T}{S}
$$

where

$$
\begin{aligned}
T & =\beta \beta_{I}+(1-\beta) \beta_{I} A^{-\alpha(1-\eta)}+\beta\left(1-\beta_{I}\right)\left(\frac{A-1}{A}\right)^{\alpha(1-\eta)} \\
S & =1-\beta
\end{aligned}
$$

Denote $\frac{h}{\eta}=T a$ and $\frac{m_{1}+m_{2}}{1-\eta}=S a$ and substitute into (21), we can derive

$$
\begin{gathered}
a=\alpha^{\frac{1}{1-\alpha}}(\mu I)^{\frac{1}{1-\alpha}} Y^{-\frac{\alpha}{1-\alpha}} \theta^{\frac{\alpha}{1-\alpha}} T^{\frac{\alpha}{1-\alpha} \eta} S^{\frac{\alpha}{1-\alpha}(1-\eta)} w^{\frac{-1}{1-\alpha}} \\
\Rightarrow \\
\left\{\begin{array}{c}
h_{B}=\eta \alpha^{\frac{1}{1-\alpha}}(\mu I)^{\frac{1}{1-\alpha}} Y^{-\frac{\alpha}{1-\alpha}} \theta^{\frac{\alpha}{1-\alpha}} T^{\frac{\alpha}{1-\alpha} \eta+1} S^{\frac{\alpha}{1-\alpha}(1-\eta)} w^{\frac{-1}{1-\alpha}} \\
m_{1 B}=\frac{(1-\eta)}{A} \alpha^{\frac{1}{1-\alpha}}(\mu I)^{\frac{1}{1-\alpha}} Y^{-\frac{\alpha}{1-\alpha}} \theta^{\frac{\alpha}{1-\alpha}} T^{\frac{\alpha}{1-\alpha} \eta} S^{\frac{\alpha}{1-\alpha}(1-\eta)+1} w^{\frac{-1}{1-\alpha}} \\
m_{2 B}=\frac{(1-\eta)(A-1)}{A} \alpha^{\frac{1}{1-\alpha}}(\mu I)^{\frac{1}{1-\alpha}} Y^{-\frac{\alpha}{1-\alpha}} \theta^{\frac{\alpha}{1-\alpha}} T^{\frac{\alpha}{1-\alpha} \eta} S^{\frac{\alpha}{1-\alpha}(1-\eta)+1} w^{\frac{-1}{1-\alpha}}
\end{array}\right.
\end{gathered}
$$


Thus we can derive the profit as

$$
\begin{aligned}
\pi_{B}= & R-w h_{B}-w m_{1 B}-w m_{2 B}-w f_{B} \\
= & \alpha^{\frac{\alpha}{1-\alpha}}(\mu I)^{\frac{1}{1-\alpha}} Y^{-\frac{\alpha}{1-\alpha}} \theta^{\frac{\alpha}{1-\alpha}} T^{\frac{\alpha}{1-\alpha} \eta}(1-\beta)^{\frac{\alpha}{1-\alpha}(1-\eta)} w^{\frac{-\alpha}{1-\alpha}}[1- \\
& \alpha(\eta T+(1-\eta)(1-\beta))]-w f_{B} \\
= & \phi_{B}(\mu I)^{\frac{1}{1-\alpha}} Y^{-\frac{\alpha}{1-\alpha}} \theta^{\frac{\alpha}{1-\alpha}}-w f_{B}
\end{aligned}
$$

which gives Equation (10).

\section{Proof of Lemma 1}

When $H$ negotiates with $M_{2}$ before $M_{1}$, by the symmetry of the bargaining game, we can write out the profit functions for the three parties $\left(H, M_{1}\right.$ and $\left.M_{2}\right)$ as

$$
\left\{\begin{array}{c}
\pi_{h}=R-P_{1}-P_{2}=\beta \beta_{I} R+\beta_{I}(1-\beta) R_{1}+\beta\left(1-\beta_{I}\right) R_{2}-w h \\
\pi_{1}=P_{1}-w m_{1}=\left(1-\beta_{I}\right)\left(R-R_{2}\right)-w m_{1} \\
\pi_{2}=P_{2}-w m_{2}=(1-\beta)\left[\beta_{I} R+\left(1-\beta_{I}\right) R_{2}-\beta_{I} R_{1}\right]-w m_{2}
\end{array}\right.
$$

The first order conditions of the suppliers are derived as

$$
\begin{aligned}
\frac{\partial \pi_{1}}{\partial m_{1}}= & \alpha\left(1-\beta_{I}\right) \mu I Y^{-\alpha} \theta^{\alpha}\left[\frac{h}{\eta}\right]^{\alpha \eta}\left[\frac{m_{1}+m_{2}}{1-\eta}\right]^{\alpha(1-\eta)-1}-w \\
\frac{\partial \pi_{2}}{\partial m_{2}}= & \alpha(1-\beta) \mu I Y^{-\alpha} \theta^{\alpha}\left[\frac{h}{\eta}\right]^{\alpha \eta}\left\{\beta_{I}\left[\frac{m_{1}+m_{2}}{1-\eta}\right]^{\alpha(1-\eta)-1}+\right. \\
& \left.\left(1-\beta_{I}\right)\left[\frac{m_{2}}{1-\eta}\right]^{\alpha(1-\eta)-1}\right\}-w
\end{aligned}
$$

First, we have $\beta_{I}\left[\frac{m_{1}+m_{2}}{1-\eta}\right]^{\alpha(1-\eta)-1}+\left(1-\beta_{I}\right)\left[\frac{m_{2}}{1-\eta}\right]^{\alpha(1-\eta)-1}>\left[\frac{m_{1}+m_{2}}{1-\eta}\right]^{\alpha(1-\eta)-1}$, that is, for the last unit of investment, the external supplier's contribution to the total revenue is higher than the internal supplier's.

Second, the external supplier has a larger Nash bargaining power than the internal supplier does, i.e. $1-\beta>1-\beta_{I}$, which means the external supplier may claim a larger share of her contribution to the total revenue than the internal supplier does. Based on these two results, we conclude that $\frac{\partial \pi_{2}}{\partial m_{2}}>\frac{\partial \pi_{1}}{\partial m_{1}}$.

As the external supplier maximizes her profits, she will make investments $m_{2}$ up to the point of $\frac{\partial \pi_{2}}{\partial m_{2}}=0$. As a result, at the optimum, we have

$$
\frac{\partial \pi_{2}}{\partial m_{2}}=0>\frac{\partial \pi_{1}}{\partial m_{1}}
$$


Given that $M_{1}$ makes investments $m_{1}$ after $M_{2}$ does and $M_{2}$ invests $m_{2}$ up to a level corresponding to $\frac{\partial \pi_{2}}{\partial m_{2}}=0$, any investment made by $M_{1}$ will have a negative marginal profit. As a consequence, the internal supplier will have no incentive to make any investment as its share of the total revenue cannot cover its costs of investments.

\section{Proof of Lemma 2}

From (6), we find that $\phi_{O}$ and $\phi_{I}$ have similar functional form except that they have different values of $\beta$ and $\beta_{I}$ with $\beta_{I}>\beta$.

Replacing $\beta_{k}$ by $\delta$, we can rewrite $\phi_{k}$ as

$$
\phi(\eta ; \delta)=\alpha^{\frac{\alpha}{1-\alpha}} \delta^{\frac{\alpha}{1-\alpha} \eta}(1-\delta)^{\frac{\alpha}{1-\alpha}(1-\eta)} w^{-\frac{\alpha}{1-\alpha}}[1-\alpha(\delta \eta+(1-\delta)(1-\eta))]
$$

We get

$$
\begin{aligned}
\frac{\partial \phi(\eta ; \delta)}{\partial \eta} & =\phi(\eta ; \delta)\left[\frac{\alpha}{1-\alpha} \ln \delta-\frac{\alpha}{1-\alpha} \ln (1-\delta)-\frac{\alpha(2 \delta-1)}{1-\alpha \delta \eta-\alpha(1-\delta)(1-\eta)}\right] \\
& >\phi(\eta ; \delta) \frac{\alpha}{1-\alpha}[\ln \delta-\ln (1-\delta)-(2 \delta-1)] \\
\frac{\partial^{2} \phi(\eta ; \delta)}{\partial \eta^{2}} & >0
\end{aligned}
$$

Let $\Delta(\delta)=\ln \delta-\ln (1-\delta)-(2 \delta-1)$, we see $\Delta^{\prime}(\delta)=\frac{1}{\delta}+\frac{1}{1-\delta}-2>0$. Thus, when $\frac{1}{2} \leq \beta<\beta_{I}$, we have $\frac{\partial \phi_{I}}{\partial \eta}$, $\frac{\partial \phi_{O}}{\partial \eta} \geq \frac{\partial \phi\left(\eta ; \frac{1}{2}\right)}{\partial \eta}>0$. When $\beta<\beta_{I}<\frac{1}{2}$, we have $\frac{\partial \phi(\eta ; \delta)}{\partial \eta}<\phi(\eta ; \delta) \frac{\alpha}{1-\alpha \delta x \eta-\alpha(1-\delta)(1-\eta)}[\ln \delta-\ln (1-\delta)-(2 \delta-1)]<0$, which leads to $\frac{\partial \phi_{O}}{\partial \eta}, \frac{\partial \phi_{I}}{\partial \eta}<0$. While $\beta<\frac{1}{2}<\beta_{I}$, we have $\frac{\partial \phi_{O}}{\partial \eta}<0<\frac{\partial \phi_{I}}{\partial \eta}$.

As $\eta \rightarrow 1, \phi(\eta ; \delta) \rightarrow \phi(1 ; \delta)=\alpha^{\frac{\alpha}{1-\alpha}} \delta^{\frac{\alpha}{1-\alpha}} w^{-\frac{\alpha}{1-\alpha}}[1-\alpha \delta]$. Since $\frac{\partial \phi(1 ; \delta)}{\partial \delta}=$ $\alpha^{\frac{\alpha}{1-\alpha}} w^{-\frac{\alpha}{1-\alpha}} \delta^{\frac{\alpha}{1-\alpha}-1} \frac{\alpha}{1-\alpha}(1-\delta)>0$, we have $\phi_{I}>\phi_{O}$ as $\beta_{I}>\beta$. When $\eta \rightarrow 0$, $\phi(\eta ; \delta) \rightarrow \phi(0 ; \delta)=\alpha^{\frac{\alpha}{1-\alpha}}(1-\delta)^{\frac{\alpha}{1-\alpha}} w^{-\frac{\alpha}{1-\alpha}}[1-\alpha(1-\delta)]=\alpha^{\frac{\alpha}{1-\alpha} \xi^{\frac{\alpha}{1-\alpha}} w^{-\frac{\alpha}{1-\alpha}}[1-}$ $\alpha \xi]$, where $\xi \equiv 1-\delta$. Thus we have $\phi_{I}<\phi_{O}$ since $\phi^{\prime}(\xi)=\alpha^{\frac{\alpha}{1-\alpha}} w^{-\frac{\alpha}{1-\alpha}} \xi^{\frac{\alpha}{1-\alpha}-1} \frac{\alpha}{1-\alpha}(1-$ $\xi)>0$ and $\xi_{I}=1-\beta_{I}<1-\beta=\xi$.

Given that $\phi(\eta ; \delta)$ is continuous and monotonic in $\eta$, we conclude from the above inequalities that there must exist a trade-off point $\eta^{*} \in(0,1)$ such that when $\eta>\eta^{*}, \phi_{I}>\phi_{O}$ holds and when $\eta<\eta^{*}, \phi_{I}<\phi_{O}$ follows.

\section{Proof of Lemma 3}


We first show that $T$ is an increasing function of $\eta$. Denote $y=\alpha \eta-\alpha$

$$
\begin{aligned}
\frac{\partial T}{\partial \eta}= & \frac{\partial y}{\partial \eta}\left[(1-\beta) \beta_{I} A^{\frac{y}{1+y}} \frac{1}{(1+y)^{2}} \ln A-\left(1-\beta_{I}\right) \beta\left(1-A^{\frac{-1}{1+y}}\right)^{-y} \ln \left(1-A^{\frac{-1}{1+y}}\right)\right. \\
& \left.+\left(1-\beta_{I}\right) \beta \frac{y}{1-A^{\frac{-1}{1+y}}} A^{\frac{-1}{1+y}} \frac{1}{(1+y)^{2}} \ln A\right]
\end{aligned}
$$

since $\frac{\partial y}{\partial \eta}=\alpha>0$, we have $\frac{\partial T}{\partial \eta}>0$.

While $\eta \rightarrow 1, T \rightarrow T(\eta=1)=\beta \beta_{I}+(1-\beta) \beta_{I}+\beta\left(1-\beta_{I}\right)>\beta_{I}$. When $\eta \rightarrow 0, T \rightarrow T(\eta=0)=\beta \beta_{I}+(1-\beta) \beta_{I}\left(\frac{1}{A}\right)^{\alpha}+\beta\left(1-\beta_{I}\right)\left(1-\frac{1}{A}\right)^{\alpha}$, which may be bigger or smaller than $\beta_{I}$ depending on the value of $\left\{\alpha, \beta, \beta_{I}\right\}$. When $T(\eta=0) \geq \beta_{I}$, then $T(\eta) \geq \beta_{I}$ throughout the domain of $\eta$; elsewhere, $T(\eta=0)<\beta_{I}$, then there must be a trade-off point $\bar{\eta}$, that when $\eta>\bar{\eta}$, $T>\beta_{I}$.

Set $\eta^{* *}=\max \left\{\eta^{*}, \bar{\eta}\right\} \geq \eta^{*}$. It must be that $T>\beta_{I}$ when $\eta \geq \eta^{* *}$.

Dividing (10) by (6), we get

$$
M(T)=\frac{\phi_{B}}{\phi_{I}}=\left(\frac{T}{\beta_{I}}\right)^{\frac{\alpha}{1-\alpha} \eta}\left(\frac{1-\beta}{1-\beta_{I}}\right)^{\frac{\alpha}{1-\alpha}(1-\eta)}\left[\frac{1-\alpha \eta T-\alpha(1-\beta)(1-\eta)}{1-\alpha \eta \beta_{I}-\alpha\left(1-\beta_{I}\right)(1-\eta)}\right]
$$

It is easy to see that $\frac{\partial M(T)}{\partial T}>0$. Thus, for $T>\beta_{I}$ when $\eta \geq \bar{\eta}$, we have

$$
\frac{\phi_{B}}{\phi_{I}}=M(T)>M\left(\beta_{I}\right)=\left(\frac{1-\beta}{1-\beta_{I}}\right)^{\frac{\alpha}{1-\alpha}(1-\eta)}\left[\frac{1-\alpha \eta \beta_{I}-\alpha(1-\beta)(1-\eta)}{1-\alpha \eta \beta_{I}-\alpha\left(1-\beta_{I}\right)(1-\eta)}\right.
$$

Denote $a=\frac{1-\alpha \eta \beta_{I}}{1-\beta_{I}}$ and $r=\frac{1-\beta}{1-\beta_{I}}$. Then $M\left(\beta_{I}\right)$ can be written as a function of $r$, that is, $L(r)=(a-\alpha(1-\eta))^{-1} r^{\frac{\alpha}{1-\alpha}(1-\eta)}(a-\alpha(1-\eta) r)$. We show that $L(r)$ is an increasing function of $r$.

$$
L^{\prime}=(a-\alpha(1-\eta))^{-1} \frac{\alpha}{1-\alpha}(1-\eta) r^{\frac{\alpha}{1-\alpha}(1-\eta)-1}[a-(1-\alpha \eta) r]>0
$$

The last inequality is established

$$
a-(1-\alpha \eta) r=\frac{1-\alpha \eta \beta_{I}-(1-\alpha \eta)\left(1-\beta_{I}\right)}{1-\beta_{I}}=\frac{\alpha \eta+\beta_{I}-2 \alpha \eta \beta_{I}}{1-\beta_{I}}>0
$$

Thus

$$
L(r)>L(1)=1
$$

As a result, we know

$$
\phi_{B}>\phi_{I} \text { when } \eta>\eta^{* *}
$$




\section{Proof of Lemma 4}

Dividing (10) by (6), we get

$$
\begin{aligned}
\frac{\phi_{B}}{\phi_{O}} & =\left[\frac{T}{\beta}\right]^{\frac{\alpha}{1-\alpha} \eta}\left[\frac{a-\alpha \eta \frac{T}{\beta}}{a-\alpha \eta}\right] \\
& =(a-\alpha \eta)^{-1} s^{\frac{\alpha}{1-\alpha} \eta}(a-\alpha \eta s)
\end{aligned}
$$

where $b=\frac{1-\alpha(1-\beta)(1-\eta)}{\beta}$ and $s=\frac{T}{\beta}$.

We first show that $T>\beta$. To get this, we must have

$$
A^{\alpha(1-\eta)} \beta \beta_{I}+(1-\beta) \beta_{I}+\beta\left(1-\beta_{I}\right)(A-1)^{\alpha(1-\eta)}>\beta A^{\alpha(1-\eta)}
$$

$\Leftrightarrow$

$$
(1-\beta) \beta_{I}>\left(1-\beta_{I}\right) \beta>\left(1-\beta_{I}\right) \beta\left[A^{\alpha(1-\eta)}-(A-1)^{\alpha(1-\eta)}\right]
$$

the last inequality holds because

$$
A^{\alpha(1-\eta)}-(A-1)^{\alpha(1-\eta)}<A-(A-1)=1
$$

Thus we know $s=\frac{T}{\beta}>1$. Let $L(s)=\frac{\phi_{B}}{\phi_{O}}=(b-\alpha \eta)^{-1} s^{\frac{\alpha}{1-\alpha} \eta}(b-\alpha \eta s)$, we can have

$$
L^{\prime}(s)=(b-\alpha \eta)^{-1} \frac{\alpha \eta}{1-\alpha} s^{\frac{\alpha}{1-\alpha} \eta-1}[b-(\alpha \eta+1-\alpha) s]>0
$$

The inequality is satisfied because

$$
T<1 \Rightarrow(\alpha \eta+1-\alpha) T<(\alpha \eta+1-\alpha)+\alpha(1-\eta) \beta
$$

so that

$$
L(s)>L(1)=1
$$

$\Rightarrow$

$$
\phi_{B}>\phi_{O}
$$

\section{Derivation of (17)}

$$
T(x)=\beta \beta_{I}+(1-\beta) \beta_{I} x^{\alpha(1-\eta)}+\beta\left(1-\beta_{I}\right)(1-x)^{\alpha(1-\eta)}
$$

Differentiating $T(x)$ with respect to $x$, we get

$$
\begin{aligned}
\frac{\partial T}{\partial x} & =\alpha(1-\eta)\left[(1-\beta) \beta_{I} x^{\alpha(1-\eta)-1}-\beta\left(1-\beta_{I}\right)(1-x)^{\alpha(1-\eta)-1}\right] \\
\frac{\partial^{2} T}{\partial x^{2}} & =\alpha(1-\eta)[\alpha(1-\eta)-1]\left[(1-\beta) \beta_{I} x^{\alpha(1-\eta)-2}+\beta\left(1-\beta_{I}\right)(1-x)^{\alpha(1-\eta)-2}\right]<0
\end{aligned}
$$


Setting $\frac{\partial T}{\partial x}=0$, we obtain

$$
x^{*}=\frac{1}{\left[\frac{\beta\left(1-\beta_{I}\right)}{\beta_{I}(1-\beta)}\right]^{\frac{1}{1-\alpha(1-\eta)}}+1}
$$

When $x>x^{*}, \frac{\partial T}{\partial x}<0$ holds; when $x<x^{*}, \frac{\partial T}{\partial x}>0$ follows.

\section{Proof of Proposition 4}

Define $\phi(z)=\alpha^{\frac{\alpha}{1-\alpha}} z^{\frac{\alpha}{1-\alpha} \eta}[t(1-\beta)]^{\frac{\alpha}{1-\alpha}(1-\eta)}\left(w^{N}\right)^{\frac{-\alpha}{1-\alpha}}[1-\alpha(\eta z+(1-\eta)(1-$ $\beta))$ ], where $z=z(x)=\beta \beta_{I}+(1-\beta) \beta_{I}(x)^{\alpha(1-\eta)}+\beta\left(1-\beta_{I}\right)(1-x)^{\alpha(1-\eta)}$. We first show that $\phi(z)$ is an increasing function of $z$.

$$
\begin{aligned}
\frac{\partial \phi(z)}{\partial z} & =\phi\left[\frac{\alpha \eta}{1-\alpha} \frac{1}{z}-\frac{\alpha \eta}{1-\alpha \eta z-\alpha(1-\eta)(1-\beta)}\right] \\
& =\alpha \eta \phi \frac{\alpha(1-\eta) \beta+(1-z)[1-\alpha(1-\eta)]}{(1-\alpha) z[1-\alpha \eta z-\alpha(1-\eta)(1-\beta)]}>0
\end{aligned}
$$

the last inequality is established as $z<1\left(z(x)<\beta \beta_{I}+(1-\beta) \beta_{I}+\beta\left(1-\beta_{I}\right)<\right.$ 1 as $x<1$ ).

Thus comparing $\phi^{N S}$ with $\phi^{S S}$, we have

$$
\begin{aligned}
\phi^{S S} & \geq \alpha^{\frac{\alpha}{1-\alpha}}\left(T^{N S}\right)^{\frac{\alpha}{1-\alpha} \eta}[t(1-\beta)]^{\frac{\alpha}{1-\alpha}(1-\eta)}\left(w^{N}\right)^{\frac{-\alpha}{1-\alpha}}\left[1-\alpha\left(\eta T^{N S}+(1-\eta)(1-\beta)\right)\right] \\
& \geq \phi^{N S}
\end{aligned}
$$

the first inequality is established as $T=T\left(x^{*}\right) \geq T\left(\frac{1}{B}\right)=T^{N S}$ (balancing advantage) and the second inequality is established by the fact that $\frac{t+B-1}{B} \geq 1$ (cost advantage).

Comparing $\phi^{S N}$ with $\phi^{S S}$, we have

$$
\begin{aligned}
\phi^{S S} & >\alpha^{\frac{\alpha}{1-\alpha}} T^{\frac{\alpha}{1-\alpha} \eta}(1-\beta)^{\frac{\alpha}{1-\alpha}(1-\eta)}\left(w^{N}\right)^{\frac{-\alpha}{1-\alpha}}\left[1-\alpha\left(\eta T+(1-\eta)(1-\beta) \frac{t C-t+1}{t C}\right)\right] \\
& \geq \phi^{S N}
\end{aligned}
$$

the first inequality is treated as the cost advantage and second inequality as the balancing advantage. It is easy to see that the second inequality is established by the fact that the function $H(m)=\alpha^{\frac{\alpha}{1-\alpha}} m^{\frac{\alpha}{1-\alpha} \eta}(1-$ $\beta)^{\frac{\alpha}{1-\alpha}(1-\eta)}\left(w^{N}\right)^{\frac{-\alpha}{1-\alpha}}\left[1-\alpha\left(m+(1-\eta)(1-\beta) \frac{t C-t+1}{t C}\right]\right.$ is increasing in $m$. While the first inequality is somewhat complicated that we derive in the following way.

$$
\frac{\phi^{S S}}{H(T)}=\frac{t^{\frac{\alpha}{1-\alpha} \eta}[1-\alpha(\eta T+(1-\eta)(1-\beta))]}{\left[1-\alpha\left(\eta T+(1-\eta)(1-\beta) \frac{t C-t+1}{t C}\right)\right]}
$$


Thus whether $\frac{\phi^{S S}}{H(T)}$ is bigger than 1 or not depends on whether $t^{\frac{\alpha}{1-\alpha} \eta}[1-$ $\alpha(\eta T+(1-\eta)(1-\beta)]$ is higher than $1-\alpha\left[\eta T+(1-\eta)(1-\beta) \frac{t C-t+1}{t C}\right]$ or not. After rearrangement, we have

$$
\begin{aligned}
& t^{\frac{\alpha}{1-\alpha} \eta}\left[1-\alpha(\eta T+(1-\eta)(1-\beta)]-\left[1-\alpha\left(\eta T+(1-\eta)(1-\beta) \frac{t C-t+1}{t C}\right)\right]\right. \\
= & \left(t^{\frac{\alpha}{1-\alpha} \eta}-1\right)\left[1-\alpha(\eta T+(1-\eta)(1-\beta)]-\alpha(1-\eta)(1-\beta) \frac{t-1}{t C}\right. \\
> & \left(t^{\frac{\alpha}{1-\alpha} \eta}-1\right)\left[1-\alpha(\eta T+(1-\eta)(1-\beta)]-\alpha(1-\eta)(1-\beta) \frac{t-1}{t}\right.
\end{aligned}
$$

the last inequality is established as $C>1$. Define $f(t)=\left(t^{\frac{\alpha}{1-\alpha} \eta}-1\right)[1-$ $\alpha(\eta T+(1-\eta)(1-\beta))]$ and $g(t)=\alpha(1-\eta)(1-\beta) \frac{t-1}{t}$. It is easy to check that both these two functions are strictly concave and increasing in $t$, i.e. $\frac{\partial f}{\partial t}>0, \frac{\partial^{2} f}{\partial t^{2}}<0, \frac{\partial g}{\partial t}>0, \frac{\partial^{2} g}{\partial t^{2}}<0$. Since $f(t=1)=g(t=1)$ and $f(t=$ $+\infty)>g(t=+\infty)$, we have that $f(t) \geq g(t)$ for $t \in[1,+\infty)$. Thus we get that $\frac{\phi^{S S}}{H(T)}>1$.

\section{Derivation of (18)}

It is easy to show that $\frac{1}{A}=\left[\frac{(1-\beta)\left(1-\beta_{I}\right)}{1+\beta \beta_{I}-2 \beta}\right]^{\frac{1}{1-\alpha(1-\eta)}}$ is a strictly convex function of $\beta_{I}$, i.e. $\frac{\partial\left(\frac{1}{A}\right)}{\partial \beta_{I}}<0, \frac{\partial^{2}\left(\frac{1}{A}\right)}{\partial \beta_{I}^{2}}>0$, and $x^{*}=\frac{1}{\left[\frac{\beta\left(1-\beta_{I}\right)}{\beta_{I}(1-\beta)}\right]^{\frac{1}{1-\alpha(1-\eta)}+1}}$ is a strictly concave function of $\beta_{I}$, i.e. $\frac{\partial x^{*}}{\partial \beta_{I}}>0, \frac{\partial^{2} x^{*}}{\partial \beta_{I}^{2}}<0$. Meanwhile, when $\beta_{I} \rightarrow \beta$, we have $\frac{1}{A} \rightarrow 1, x^{*} \rightarrow \frac{1}{2}$, and thus $\frac{1}{A}>x^{*}$; when $\beta_{I} \rightarrow 1$, we obtain $\frac{1}{A} \rightarrow 0$, $x^{*} \rightarrow 1$, and hence $\frac{1}{A}<x^{*}$. So, there exists a unique point $\beta_{I}^{*}=f(\beta, \alpha, \eta)$ such that when $\beta_{I}<\beta_{I}^{*}, \frac{1}{A}>x^{*}$ applies and when $\beta_{I}>\beta_{I}^{*}, \frac{1}{A}<x^{*}$ follows.

\section{Proof of Proposition 5}

From equations (11), it is easy to get $\left(h^{N S}, m^{N S}\right)$ and $\left(h^{S S}, m^{S S}\right)$ as

$$
\begin{gathered}
\left\{\begin{array}{l}
h^{N S}=\eta \alpha^{\frac{1}{1-\alpha}}(\mu I)^{\frac{1}{1-\alpha}} Y^{-\frac{\alpha}{1-\alpha}} \theta^{\frac{\alpha}{1-\alpha}}\left(T^{N S}\right)^{\frac{\alpha}{1-\alpha} \eta+1}[t(1-\beta)]^{\frac{\alpha}{1-\alpha}(1-\eta)}\left(w^{N}\right)^{\frac{-\alpha}{1-\alpha}} \\
\left.m^{N S}=\eta \alpha^{\frac{1}{1-\alpha}}(\mu I)^{\frac{1}{1-\alpha}} Y^{-\frac{\alpha}{1-\alpha}} \theta^{\frac{\alpha}{1-\alpha}}\left(T^{N S}\right)^{\frac{\alpha}{1-\alpha}} \eta t(1-\beta)\right]^{\frac{\alpha}{1-\alpha}(1-\eta)+1}\left(w^{N}\right)^{\frac{-\alpha}{1-\alpha}}
\end{array}\right. \\
\left\{\begin{array}{l}
h^{S S}=\eta \alpha^{\frac{1}{1-\alpha}}(\mu I)^{\frac{1}{1-\alpha}} Y^{-\frac{\alpha}{1-\alpha}} \theta^{\frac{\alpha}{1-\alpha}} T^{\frac{\alpha}{1-\alpha} \eta+1}[t(1-\beta)]^{\frac{\alpha}{1-\alpha}(1-\eta)}\left(w^{N}\right)^{\frac{-\alpha}{1-\alpha}} \\
m^{S S}=\eta \alpha^{\frac{1}{1-\alpha}}(\mu I)^{\frac{1}{1-\alpha}} Y^{-\frac{\alpha}{1-\alpha}} \theta^{\frac{\alpha}{1-\alpha}} T^{\frac{\alpha}{1-\alpha} \eta}[t(1-\beta)]^{\frac{\alpha}{1-\alpha}(1-\eta)+1}\left(w^{N}\right)^{\frac{-\alpha}{1-\alpha}}
\end{array}\right.
\end{gathered}
$$


where

$$
\begin{aligned}
T^{N S} & =\beta \beta_{I}+(1-\beta) \beta_{I}\left(\frac{1}{B}\right)^{\alpha(1-\eta)}+\beta\left(1-\beta_{I}\right)\left(1-\frac{1}{B}\right)^{\alpha(1-\eta)} \\
B & =\left[\frac{t(1-\beta)-\beta\left(1-\beta_{I}\right)}{(1-\beta)\left(1-\beta_{I}\right)}\right]^{\frac{1}{1-\alpha(1-\eta)}}>1 \\
T & =\beta \beta_{I}+(1-\beta) \beta_{I}\left(\frac{1}{A}\right)^{\alpha(1-\eta)}+\beta\left(1-\beta_{I}\right)\left(1-\frac{1}{A}\right)^{\alpha(1-\eta)} \\
A & =\left[\frac{1+\beta \beta_{I}-2 \beta}{(1-\beta)\left(1-\beta_{I}\right)}\right]^{\frac{1}{1-\alpha(1-\eta)}}>1
\end{aligned}
$$

Dividing $h^{N S}$ by $h^{S S}$ and $m^{N S}$ by $m^{S S}$, we get

$$
\frac{h^{N S}}{h^{S S}}=\left(\frac{T^{N S}}{T}\right)^{\frac{\alpha}{1-\alpha} \eta+1} \text { and } \frac{m^{N S}}{m^{S S}}=\left(\frac{T^{N S}}{T}\right)^{\frac{\alpha}{1-\alpha} \eta}
$$

Thus $\frac{h^{N S}}{h^{S S}}$ and $\frac{m^{N S}}{m^{S S}}$ are both increasing in $\frac{T^{N S}}{T}$. For convenience of expression, let $G$ denote $\frac{T^{N S}}{T}$. Then

$$
\frac{\partial G}{\partial t}=\frac{G}{T^{N S}}\left(\frac{\partial T^{N S}}{\partial t}\right)=\frac{G}{T^{N S}}\left(\frac{\partial T^{N S}}{\partial B} \times \frac{\partial B}{\partial t}\right)
$$

As

$$
\frac{\partial B}{\partial t}=\frac{B}{1-\alpha(1-\eta)} \frac{1-\beta}{t(1-\beta)-\left(1-\beta_{I}\right) \beta}>0
$$

we have

$$
\frac{\partial G}{\partial t} \sim \frac{\partial T^{N S}}{\partial B} \sim\left[\frac{1}{(B-1)^{1-\alpha(1-\eta)}}-\frac{1}{\left(x^{*}-1\right)^{1-\alpha(1-\eta)}}\right]
$$

Let $H$ denote $\frac{1}{(B-1)^{1-\alpha(1-\eta)}}-\frac{1}{\left(x^{*}-1\right)^{1-\alpha(1-\eta)}}$. It is easy to see

$$
\frac{\partial H}{\partial t}=-[1-\alpha(1-\eta)](B-1)^{\alpha(1-\eta)-2} \frac{\partial B}{\partial t}<0
$$

Thus $\frac{1}{(B-1)^{1-\alpha(1-\eta)}}-\frac{1}{\left(x^{*}-1\right)^{1-\alpha(1-\eta)}}$ is decreasing in $t$. When $t \rightarrow 1, B \rightarrow A<$ $x^{*}$, then $\frac{1}{(B-1)^{1-\alpha(1-\eta)}}-\frac{1}{\left(x^{*}-1\right)^{1-\alpha(1-\eta)}}>0$ and as a result, $\frac{\partial G}{\partial t}>0$; when $t \rightarrow \infty$, $B \rightarrow \infty$, then $\frac{1}{(B-1)^{1-\alpha(1-\eta)}}-\frac{1}{\left(x^{*}-1\right)^{1-\alpha(1-\eta)}}<0$ and as a result, $\frac{\partial G}{\partial t}<0$. We therefore conclude that $G$ is first increasing and then decreasing in $t$.

Since $G(t=1)=1$ and $G(t=\infty)=\frac{\beta}{T}<1$, we know that $G>1$ and thus $\left(h^{N S}, m^{N S}\right)>\left(h^{S S}, m^{S S}\right)$ hold when $t$ is not so large and $G<1$ and thus 
$\left(h^{N S}, m^{N S}\right)<\left(h^{S S}, m^{S S}\right)$ hold when $t$ becomes sufficiently large. Given the complementarity between $h$ and $m$ in the Cobb-Douglas production function (3), we know that $N S$ achieves a higher level of production efficiency than $S S$.

\section{Proof of Proposition 6}

We also can get the optimal $\left(h^{S N}, m^{S N}\right)$ from equation (11)

$$
\left\{\begin{array}{l}
h^{S N}=\eta \alpha^{\frac{1}{1-\alpha}}(\mu I)^{\frac{1}{1-\alpha}} Y^{-\frac{\alpha}{1-\alpha}} \theta^{\frac{\alpha}{1-\alpha}}\left(T^{S N}\right)^{\frac{\alpha}{1-\alpha} \eta+1}[(1-\beta)]^{\frac{\alpha}{1-\alpha}(1-\eta)}\left(w^{N}\right)^{\frac{-\alpha}{1-\alpha}} \\
m^{S N}=\eta \alpha^{\frac{1}{1-\alpha}}(\mu I)^{\frac{1}{1-\alpha}} Y^{-\frac{\alpha}{1-\alpha}} \theta^{\frac{\alpha}{1-\alpha}}\left(T^{S N}\right)^{\frac{\alpha}{1-\alpha} \eta}[(1-\beta)]^{\frac{\alpha}{1-\alpha}(1-\eta)+1}\left(w^{N}\right)^{\frac{-\alpha}{1-\alpha}}
\end{array}\right.
$$

where

$$
\begin{aligned}
T^{S N} & =\beta \beta_{I}+(1-\beta) \beta_{I}\left(\frac{1}{C}\right)^{\alpha(1-\eta)}+\beta\left(1-\beta_{I}\right)\left(1-\frac{1}{C}\right)^{\alpha(1-\eta)} \\
C & =\left[\frac{(1-\beta)-t \beta\left(1-\beta_{I}\right)}{t(1-\beta)\left(1-\beta_{I}\right)}\right]^{\frac{1}{1-\alpha(1-\eta)}}>1 \\
1 & \leq t \leq \frac{1-\beta}{1-\beta_{I}}
\end{aligned}
$$

Dividing $h^{S N}$ by $h^{S S}$ and $m^{S N}$ by $m^{S S}$, we get

$$
\frac{h^{S N}}{h^{S S}}=\left(\frac{T^{S N}}{T}\right)^{\frac{\alpha}{1-\alpha} \eta+1}\left(\frac{1}{t}\right)^{\frac{\alpha}{1-\alpha}(1-\eta)}, \text { and } \frac{m^{S N}}{m^{S S}}=\left(\frac{T^{N S}}{T}\right)^{\frac{\alpha}{1-\alpha} \eta}\left(\frac{1}{t}\right)^{\frac{\alpha}{1-\alpha}(1-\eta)+1}
$$

For convenience of expression, let $u=\frac{1}{t}$ and $N=T(x(u))^{\frac{\alpha}{1-\alpha} \eta+1} u^{\frac{\alpha}{1-\alpha}(1-\eta)}$, where $T(x)=\beta \beta_{I}+(1-\beta) \beta_{I} x^{\alpha(1-\eta)}+\left(1-\beta_{I}\right) \beta(1-x)^{\alpha(1-\eta)}, x(u)=$ $\left[\frac{(1-\beta)\left(1-\beta_{I}\right)}{u(1-\beta)-\beta\left(1-\beta_{I}\right)}\right]^{\frac{1}{1-\alpha(1-\eta)}}$ and $u$ lies in the interval of $\left[\frac{1-\beta_{I}}{1-\beta}, 1\right]$. Taking logarithm of $M$, we have

$$
\ln N=\left(\frac{\alpha}{1-\alpha} \eta+1\right) \ln T(x)+\frac{\alpha}{1-\alpha}(1-\eta) \ln u
$$

Thus

$$
\frac{\partial N}{\partial u}=N\left[\left(\frac{\alpha}{1-\alpha} \eta+1\right) \frac{1}{T} \frac{\partial T}{\partial x} \frac{\partial x}{\partial u}+\frac{\alpha}{1-\alpha}(1-\eta) \frac{1}{u}\right]
$$

It has two parts, the second of which is definitely positive. We need to determine the sign of the first part. As

$$
\frac{\partial x}{\partial u}=\frac{-x}{1-\alpha(1-\eta)}\left[\frac{(1-\beta)}{(1-\beta) u-\left(1-\beta_{I}\right) \beta}\right]<0
$$


and

$$
\frac{\partial T}{\partial x}=\alpha(1-\eta)\left[(1-\beta) \beta_{I} x^{\alpha(1-\eta)-1}-\beta\left(1-\beta_{I}\right)(1-x)^{\alpha(1-\eta)-1}\right]
$$

The sign of $\frac{\partial N}{\partial u}$ depends on that of $\frac{\partial T}{\partial x}$. When $\frac{\partial T}{\partial x}<0$, which happens if $u$ is low and $x<x^{*}$, we have $\frac{\partial N}{\partial u}>0$. In contrast, when $\frac{\partial T}{\partial x}>0$, which occurs if $u$ is high and $x>x^{*}$, the sign of $\frac{\partial N}{\partial u}$ is ambiguous. In the following we consider this latter case, i.e. $x>x^{*}$ and $\frac{\partial T}{\partial x}>0$.

Rewrite $\frac{\partial N}{\partial u}$ as

$$
\frac{\partial N}{\partial u}=\frac{N}{u}\left[\frac{\alpha}{1-\alpha}(1-\eta)+\left(\frac{\alpha}{1-\alpha} \eta+1\right) g(u)\right]
$$

where $g(u)=\frac{u}{T} \frac{\partial T}{\partial x} \frac{\partial x}{\partial u}$

$$
\frac{\partial g(u)}{\partial u}=\frac{1}{T} \frac{\partial T}{\partial x} \frac{\partial x}{\partial u}-\frac{u}{T^{2}}\left(\frac{\partial T}{\partial x} \frac{\partial x}{\partial u}\right)^{2}+\frac{u}{T} \frac{\partial^{2} T}{\partial x^{2}}\left(\frac{\partial x}{\partial u}\right)^{2}+\frac{u}{T} \frac{\partial T}{\partial x} \frac{\partial^{2} x}{\partial u^{2}}<0
$$

as $\frac{\partial^{2} T}{\partial x^{2}}<0, \frac{\partial T}{\partial x}>0, \frac{\partial^{2} x}{\partial u^{2}}>0$. So

$$
\begin{aligned}
\frac{\partial N}{\partial u} \geq & N\left[\frac{\alpha}{1-\alpha}(1-\eta)+\left(\frac{\alpha}{1-\alpha} \eta+1\right) g(u=1)\right] \\
= & N \frac{\alpha}{1-\alpha}(1-\eta)[1- \\
& \left.\frac{1-\beta}{1-\beta-\beta\left(1-\beta_{I}\right)} \frac{\beta_{I}(1-\beta)-\beta\left(1-\beta_{I}\right)(A-1)^{\alpha(1-\eta)-1}}{\beta \beta_{I} A^{\alpha(1-\eta)}+(1-\beta) \beta_{I}+\left(1-\beta_{I}\right) \beta(A-1)^{\alpha(1-\eta)}}\right]
\end{aligned}
$$

It is easy to see that the expression on the right hand side is bigger than zero. So $\frac{\partial N}{\partial u}>0$ holds.

Now we know that $N$ is always increasing in $u$. When $u$ reaches its maximum, i.e., $u=1, N$ also reaches the maximum, i.e., $N_{\max }=T^{\frac{\alpha}{1-\alpha} \eta+1}$. Under this circumstance, $\left(h^{S N}, m^{S N}\right)$ and $\left(h^{S S}, m^{S S}\right)$ are equal. This implies that when $u<1, N<N_{\max }$ and thus $\left(h^{S N}, m^{S N}\right) \leq\left(h^{S S}, m^{S S}\right)$ holds. 